\title{
EL DERECHO A DECIDIR Y LA CONSTITUCIÓN POLÍTICA DE LA CIUDAD DE MÉXICO
}

THE RIGHT TO DECIDE AND THE CONSTITUTION OF THE MEXICO CITY

\section{Armando Rendón Corona*}

\section{RESUMEN}

El artículo trató sobre la consulta al pueblo como uno de los derechos de soberanía (elegir representantes, controlarlos y destituirlos), cuya finalidad es la toma de decisiones por la ciudadanía y la orientación de la acción del Estado. Se abordaron cuestiones como el ámbito, el objeto, la tipología y los convocantes. En específico, trató de la adopción de estos derechos en la primera Constitución Política de la Ciudad de México (СРСм), contrastados con la regulación de la consulta en el artículo 35 de la Constitución Política de los Estados Unidos Mexicanos. Abordó las definiciones y reglas de los mecanismos de democracia directa, específicamente plebiscito, referéndum y el referéndum revocatorio de mandato de los funcionarios elegidos y aplicaciones de la iniciativa legislativa popular.

Palabras clave: Participación ciudadana, consulta al pueblo, plebiscito, referéndum, revocación de mandato, iniciativa popular.

\section{ABSTRACT}

The article deals with the consultation of the people as one of the rights of sovereignty (to elect representatives, control and dismiss them), whose purpose is the decision making by the citizens and the orientation of the action of the State. Issues such as scope, object, typology and conveners are addressed. Specifically, it deals with the adoption of these rights in the first Political Constitution of Mexico City, contrasted with the regulation of the consultation in article 35 of the National Political Constitution. Addresses the definitions and rules of exercise of the consultations, specifically plebiscite, referendum and the recall referendum of elected officials and applications of the popular legislative initiative.

Keywords: Citizen participation, consultation with the people, plebiscite, referendum, revocation of mandate, popular initiative.

Recibido 8 de junio de 2017 y aceptado 16 de diciembre de 2019

${ }^{*}$ Doctor en Ciencia Política. Profesor-Investigador de la Universidad Autónoma Metropolitana, Unidad Iztapalapa. 


\section{DERECHOS DE SOBERANÍA POPULAR}

Este artículo se sitúa en una etapa anterior a las elecciones del i de julio de 2018 que anunciaron el comienzo del fin del régimen autoritario; el pueblo, usando la vía democrática electoral decidió un cambio de rumbo.

En este artículo nos ocupamos de un campo de derechos que se pueden designar como el derecho a decidir, un derecho de soberanía popular, con el cual la ciudadanía participa en la toma de decisiones políticas mediante la consulta, decisiones que el Estado debe acatar. Participar en las decisiones políticas tiene muchas modalidades, pero aquí nos limitamos a la convocatoria a los ciudadanos a expresar su voluntad mediante el referéndum y el plebiscito, respondiendo a la(s) pregunta(s) que se le presenta(n). ${ }^{\mathrm{I}}$

El derecho de consulta al pueblo es cada vez más demandado y apremiante en una sociedad como la mexicana casi desprovista de derechos de ciudadanía. La cuestión cobra importancia en proporción a la crisis de representatividad de las élites políticas, características del régimen autoritario, volcadas al beneficio privado a costa del interés público y subordinadas a poderes supranacionales.

\section{UN RÉGIMEN QUE TERMINA Y OTRO QUE COMIENZA}

El régimen político mexicano, nominalmente definido como república democrática y representativa, dista mucho de serlo; fuerzas monopolizadoras y excluyentes de la clase capitalista han vaciado de significado esos principios. La ciudadanía, como entidad esencial de la república, sufre una degradación acelerada; el clientelismo y la manipulación del voto han producido el fenómeno de los no-ciudadanos, aquellos que renuncian a sus derechos de ciudadanía a cambio de míseros beneficios. Presenciamos, no sin resistencias, la anulación práctica de los derechos humanos, laborales, a la seguridad, a

${ }^{\mathrm{I}}$ El concepto de derecho a decidir tiene varias aplicaciones; las feministas lo usan en defensa de la interrupción del embarazo, otros sobre la eutanasia. En España, muchos lo identifican con el derecho de secesión, que los autonomistas catalanes y vascos pretenden conseguir mediante referéndum, en los que han participado los españolistas partidarios del centralismo del Estado (Bárcena, 20I4). 
la propiedad social y pública y muchos otros. El derecho al sufragio ha sido tergiversado por una maquinaria que sacrifica todo a favor de una clase dominante paradójicamente apoyada en los pobres y en la fuerza.

¿Qué significado tiene el principio de soberanía popular en que se funda la república? Una concepción repetida a lo largo de la historia de la república ha reducido la soberanía del pueblo, poder último, al derecho de elegir gobernantes y representantes, y casi vemos como único ese limitado concepto de democracia. ${ }^{2}$ De hecho, el verdadero soberano es el Estado, no en el sentido de soberanía nacional en las relaciones interestatales, sino en el sentido monárquico o dictatorial. Después del acto de elegir, el pueblo soberano se diluye, el Estado ejerce la soberanía a través de sus órganos, es decir, de las autoridades políticas y administrativas. Son ellas las intérpretes de la nación, deciden los límites de las intervenciones de la ciudadanía (Constitución Política de los Estados Unidos Mexicanos [CPEUM], artículo 4I). El ciudadano «elige» y con ese acto ha perdido el poder, lo ha entregado al representante que queda libre de conducirse o no como tal; él mismo fija las reglas de sus atribuciones y se fiscaliza. No es un servidor público, como eufemísticamente se autodenominan, sino poder pleno.

${ }^{2}$ La soberanía reside en el pueblo, entendido también como nación o colectividad nacional, calidad que no puede deshacerse o transferirse en provecho de nadie, ni del Estado ni de sus autoridades. El adjetivo soberano designa un poder que no admite ningún otro por encima de él, que no se subordina a ninguna otra autoridad superior. A su vez, el Estado, organización del poder, no puede ser soberano porque está subordinado, él es la expresión de la voluntad del soberano. Tradicionalmente, se repite la confusión que identifica la nación con el Estado, y hasta con el titular del poder del Estado. Según lo asentó G. Burdeau (I985), ha sido un error creer «que los gobernantes ponen en práctica el poder del soberano cuando no hacen más que ejercer el poder del Estado» (pp. 378-393). La segunda confusión consiste en identificar el órgano del poder estatal con su condición de representante; para el jurista, los gobernantes son investidos de las prerrogativas del poder público, cosa distinta a la soberanía política. El soberano determina el sentido en que debe ser utilizado el poder del Estado, detenta el dominio del principio rector de la vida estatal y la elección de los gobernantes. El elegido representa a la nación, de ella obtiene su mandato y «decide por ella». Nadie puede ejercer autoridad en el Estado sin haber sido habilitado por él. Por consiguiente, la ley expresa la voluntad general, y el órgano legislativo deriva de ella las decisiones y la autoridad para legislar. La soberanía es poder constituyente, el soberano está por encima de la Constitución, no depende de ella porque la crea (Burdeau, I985, pp. 385, 387, 392). 
Tratándose del poder institucional, se ha hecho creer que todo el poder reside en un solo sitio: el Estado; la sociedad es el objeto pasivo sobre el que realiza su acción. Delegar es la palabra clave por la que la soberanía se transfiere, pero ¿no se da por aceptado que la soberanía popular es inalienable e imprescriptible?

Delegar significa transferir, no es una comisión condicionada y transitoria a un delegado para que ejecute la voluntad de los ciudadanos en su conjunto; al transferir su atributo supremo, el ciudadano sueña que su soberanía sigue intacta, que el poder sigue residiendo en el pueblo. Cree en la intangibilidad de la soberanía y los primeros interesados en cultivar tal creencia son los delegados.

Por todas partes se percibe que el poder del Estado se separa cada vez más de la sociedad y se sitúa por encima de ella, se independiza o autonomiza, es decir, se vuelve poder indeterminado. Cualquier intento de limitarlo o influir sobre él no va más allá de hacerlo en cierto grado; las iniciativas difusas provenientes de la sociedad (la opinión pública, las movilizaciones) quedan atrapadas en un catálogo de prohibiciones institucionales, hasta que una crisis desmorona las otrora inquebrantables bases del poder y los gobernantes son defenestrados.

El derecho a elegir gobernantes constituye el momento supremo de investidura de quienes ejercen el derecho a gobernar; es enaltecido y consagrado como única fuente del poder, sin reconocer que esa es solo una de sus propiedades. El derecho a elegir es inseparable del derecho de vigilar que el comportamiento del mandatario se ajuste al mandato y del derecho de quitar el mandato. Los derechos a vigilar y destituir históricamente fueron enviados al ostracismo (exilio y silencio), pues esa ha sido la condición para que el Estado se autonomice de la sociedad. La reducción del principio de soberanía al derecho de elegir gobernantes oscurece sus otras dos dimensiones: vigilar y destituir.

Queda por saber cómo la ciudadanía forma y expresa su voluntad, cómo esclarece sus designios, cómo elabora su mandato. Eso también pertenece al ámbito de su soberanía, protegida por el derecho intangible a la libertad: de opinión, de expresión, de información, de deliberación, de asociación, reunión y manifestación. 
Para el poder instituido no hay cosa más amenazante que el ciudadano exigente y las asambleas deliberantes; las libertades deben tener límites, nos dicen, se trata de impedir que impugnen de manera efectiva los propósitos de las élites del poder y, por encima de todo, impedir que las ejerzan. Eso depende de la capacidad de acción ciudadana; la cuestión es ¿cómo se forma la voluntad popular, cómo esclarece sus voliciones? Hay que considerar que la monopolización del poder está ligada a la pasividad social, y que la ciudadanía tendrá que afanarse en reaccionar frente a las estrategias de desarticulación social, ideologización planificada de los monopolios mediáticos, el modelo educativo de obediencia, el encuadramiento, cuando no el abatimiento de las asociaciones civiles y, sobre todo, la meticulosa monopolización de las esferas decisorias.

El sujeto de la monopolización es un bloque en el poder conformado por la heterogénea clase política, incluidos los poderes extrainstitucionales o fácticos: el mediático, delincuencial, eclesiástico, trasnacional y, por encima de todos, el poder de la oligarquía capitalista global. Lo único que queda fuera es el poder popular. En esos ámbitos se encierra la representación política. En esas condiciones no extraña que la democracia representativa sea impugnada por no ser suficientemente democrática y representativa; en los más diversos tonos y latitudes se habla de la crisis de representatividad, requisito insustituible de la legitimidad. Se discute sobre la pérdida de significado de la representación y la legitimidad ante el fenómeno global de la oligarquización del poder, apoyado en estrategias de sustitución de la legitimidad democrática por la apariencia, con técnicas fraudulentas y persuasivas para conseguir credulidad y conformidad, consentimiento y obediencia al poder, pero no bastan.

Estas condiciones no han podido impedir que se extienda la convicción de la ilegitimidad de quienes ejercen el poder, el engaño como forma de dominación choca con las realidades de la polarización de la sociedad mexicana entre riqueza y pobreza con su cauda de desintegración social; por consiguiente, resurge una y otra vez el conflicto entre democracia y monopolización del poder. Si el bloque dominante abandona la legitimidad real renuncia al consentimiento voluntario; llegado a ese límite, aparece el verdadero asiento del poder: la coerción, el empleo de la fuerza unas veces 
graduada y otras desbocada; ${ }^{3}$ si no ha de obedecer el pueblo por propio consentimiento, tendrá que hacerlo por miedo. La violencia vivida durante muchos años en México es opuesta a la violencia legítima del Estado detentador del monopolio legítimo de la fuerza, pues no hay tal monopolio legítimo; el Estado recurre a ella con fines privados, comparte la violencia antisocial con los grupos paramilitares privados, con la delincuencia organizada y la violencia empresarial.

Ahora bien, ninguno de los cuestionamientos expuestos va en el sentido de negar la democracia representativa, ni del principio representativo en el amplio sentido; por el contrario, se trata de rescatar el sistema republicano subvertido por el régimen autoritario que lo ha reducido a mera «fórmula política», por usar la expresión de G. Mosca.

No es la sociedad la que establece un equilibrio republicano con el Estado. El mundo formal transcurre por separado del irreductible conflicto real generado por la demanda social insatisfecha en conflicto con la privatización del Estado; el centro de la confrontación se produce entre un modelo de acumulación por desposesión implantado por el bloque gobernante y la resistencia social pugnante por la redistribución del ingreso y la riqueza. ${ }^{4} \mathrm{En}$ ese sentido, el Estado se presenta como conjunto orgánico, como unidad de aparatos de poder frente a una sociedad fragmentada. El equilibrio de fuerzas no puede resultar de tal desigualdad; la única salida es profundizar la democracia.

${ }^{3}$ Varios ordenamientos legales sobre el uso de la fuerza contra la sociedad civil están siendo debatidos en el Congreso de la Unión y otros ya han sido aprobados; particularmente peligrosas son las iniciativas de reforma al artículo 29 de la Constitución Política de los Estados Unidos Mexicanos sobre el Estado de sitio y la iniciativa de Ley de Seguridad Interior que autorizaría la amplia intervención de las fuerzas armadas en tareas propias de la policía.

${ }^{4}$ Las formas de despojo que caracterizaron la acumulación de capital en los comienzos del capitalismo no pertenecen solamente a esa etapa histórica, sino que son consustanciales al capitalismo. David Harvey (2005) lo dice así: «Dado que denominar "primitivo” u "originario" a un proceso en curso parece desacertado, en adelante voy a sustituir estos términos por el concepto de "acumulación por desposesión”" (p. II3). Las prácticas de depredación, fraude y robo, «juegan un rol aún más importante que el que habían jugado en el pasado»; una de esas prácticas de acumulación por desposesión es «La vuelta al dominio privado de derechos de propiedad común» (p. II5), lo cual explica la relevancia que ha cobrado la demanda social de recuperar el contenido de lo público. 


\section{EL DERECHO A DECIDIR}

El establecimiento de una nueva relación entre dominantes y dominados, entre sociedad y Estado, supone crear un nuevo equilibrio cuyo fin sea limitar y revertir las tendencias a la monopolización y a la arbitrariedad del ejercicio del poder político, mediante fórmulas de redistribución del poder hacia la sociedad. La cuestión es cómo centrar el principio de soberanía de la sociedad civil en la vida pública, desenvolviendo el concepto de democracia en nuevas esferas de lo público social y de lo público estatal.

Forman parte de esa tendencia los derechos a intervenir en la planificación de la economía y del territorio, el derecho al control social sobre el Estado, el derecho a la autogestión de los asuntos comunitarios y locales. Todos ellos derechos de soberanía que vienen configurando en varios países latinoamericanos una nueva institucionalidad caracterizada por la participación directa de personas y colectividades en la gestión de los asuntos públicos. La nueva cultura participativa es consustancial a la formación de la voluntad popular desde las pequeñas unidades y en gran escala.

La vía democrática de la consulta al pueblo es uno de los medios capaces de contender contra la tendencia a la privatización del Estado en sus múltiples modalidades. Contiende contra la pérdida del sentido de lo público en el Estado, la fragmentación social, la disolución del sentido de unidad nacional, por tanto, de racionalidad de lo nacional político. La tendencia a aislar al Estado de su sociedad ha sido laboriosamente tramada para privilegiar el interés de la clase capitalista y los aspirantes a pertenecer a ella. El interés privado de cada uno de los poderosos y de todos en conjunto se ha adueñado de las funciones del Estado, haciendo que la decisión política esté condicionada por los intereses particulares; en ese sentido, se entiende la desintegración de lo público estatal.

En la historia republicana no ha existido el predominio del sentido de lo público, el interés general determinado por la voluntad expresa de la sociedad misma como principio normativo de la acción del Estado; de ahí la inconveniencia de hablar de una restauración o restablecimiento del interés general, que a lo más ha tenido una existencia precaria y episódica.

Es más apropiado decir estatuir el interés general en la esfera de lo público estatal. El cuerpo electoral al tomar en sus manos ciertas decisiones da vida 
al principio de soberanía del pueblo, no para encumbrar a los portadores del poder, sino para dictar un rumbo a la acción estatal. Cada vez que se consulta al pueblo se actualiza la República, entendida como organización de los ciudadanos, esclareciendo la voluntad o las voluntades que la animan.

La sociedad heterogénea segmentada en clases sociales, culturas, etnias, intereses nacidos del modo de vida y de trabajo, tiene la ocasión de esclarecer el carácter más general de sus intereses, de dirimir mediante la interacción comunicacional lo que conviene o no para dar rumbo a la acción de los ciudadanos y del Estado. Esto significa que las visiones vagas, los propósitos ocultos o las necesidades reales de cada sector social se ponen en debate, se ponen en juego los derechos y libertades indispensables en la formación de la voluntad popular.

El principio abstracto cobra vida en el proceso de diferenciación de los intereses y de las voluntades, finalmente sintetizadas en opciones sintéticas: Sí o No a tal cosa; la sociedad dividida, escoge y el principio de mayoría se impone. Ese es el proceder democrático.

Otra cuestión relevante es si el cuerpo electoral debe intervenir en todo momento y en cualquier asunto. Los argumentos contrarios a la democracia plebiscitaria siempre insisten en la imposibilidad técnica de consultar a cada momento a los ciudadanos, o se arguye del peligro de la manipulación de la opinión pública por los medios de comunicación monopolizados; se insiste en que el pueblo desinformado e inculto no puede obrar racionalmente ante materias complejas, que la indiferencia política de las masas deja el campo libre a las clases superiores, más conocedoras y participativas. La lista de objeciones puede continuar, y en cada una es posible encontrar elementos observables.

Las experiencias muestran que no se convoca al pueblo a opinar y decidir sobre todas las cuestiones; en las constituciones que incluyen el principio referendario se acostumbra emplear el concepto impreciso de «cuestiones trascendentes» o relevantes, o las más significativas para un conjunto social. No se consulta a todos sobre todas las cuestiones; de otro modo, se llegaría al absurdo de prescindir de las instituciones encargadas de las funciones públicas y los funcionarios responsables cesarían en sus funciones. Se apela a la decisión popular cuando la minoría gobernante no debe asumir toda la responsabilidad, sobre todo cuando las consecuencias de una decisión 
benefician o perjudican a todos, pero también se apela al referéndum o al plebiscito para salir del estancamiento cuando las élites no pueden o no quieren tomar la decisión.

Los poseedores del poder concentrado estarán radicalmente en contra de perder el monopolio de la decisión y dejar que un negocio reservado sea del dominio público; les ha funcionado bien evadir el derecho a la consulta, pero si no pudieran evitarlo la harían lo más inaccesible y poco frecuente. Por eso mismo, contra la concentración y autonomía de las élites del poder es necesario fundamentar el Estado sobre una ancha base democrática, es decir, en el consentimiento, la elección genuina de los gobernantes, abrir a la participación ciudadana la definición de las políticas y en el funcionamiento del Estado.

Si se trata de que el cuerpo electoral tome la decisión, esta tiene que ser obligatoria para los órganos del Estado y válida para el conjunto social. Como toda norma social, no puede entenderse como intemporal; la decisión tomada ha de pasar por la prueba de su aplicación, y nuevas configuraciones en la relación de fuerzas entre clases y sectores sociales harán nuevas modificaciones; la dinámica de la relación entre fuerzas sociales es equivalente a la competencia por el poder entre partidos políticos.

Las regulaciones impuestas a la frecuencia de las consultas y el tipo de decisiones que son sometidas a la sociedad técnicamente han de tomar en cuenta el esfuerzo, tiempo y modo de formación de la opinión pública. El instrumento de la consulta al pueblo tiene limitaciones, resuelve algunas cuestiones de vez en cuando, no es el remedio para todo. En otros espacios, si se garantiza el juego democrático entre los intereses sociales contradictorios, las fuerzas sociales dirimen sus intereses por otras vías. Desde un punto de vista general, la frecuencia depende de las urgencias de la realidad; entre más frecuente, mejor; entre menos asuntos intocables haya es mejor. A mayor oligarquización, mayor necesidad de apelar a las consultas.

\section{EL ÁMBITO SOCIAL DE LA CONSULTA}

Hasta aquí parece que la consulta al pueblo se circunscribe al espacio del Estado a escala nacional, pero lo mismo vale para otros niveles geopolíticos, los estados, regiones, municipios y entidades submunicipales. Todo esto 
pertenece a los órganos del Estado, pero sus aplicaciones se extienden a las esferas sociales: una demarcación territorial, sociocultural o económica, con independencia de las delimitaciones geográficas de municipios y estados; por ejemplo, un sector social como los pueblos originarios, un sector profesional, por caso los trabajadores de la salud o de la educación. Las consultas pueden corregir la elitización en el interior de los partidos políticos, los miembros de instituciones pueden reconducir iglesias o escuelas, así como a una organización social como un sindicato burocratizado o una asociación profesional elitizada. En general, la consulta añade un instrumento participativo a sus dinámicas de acción y contribuye al aprendizaje de la ciudadanía.

Todas estas prácticas referendarias requieren quedar formalizadas en el catálogo de derechos ciudadanos con el fin de acelerar la superación del antiguo régimen. Se da por supuesto que son prácticas en el ámbito autónomo de la sociedad civil, de los grupos sociales; fijar las reglas y determinar las materias de la consulta son derechos de la sociedad civil.

\section{OBJETO DE LA CONSULTA}

Se recurre a la consulta para dirimir asuntos considerados de gran importancia, relevantes, trascendentes o excepcionales; por ejemplo, en asuntos que definen el interés nacional, las atribuciones o la organización del Estado. No se limita a cuestiones no previstas en la legislación, sino a la legislación misma, incluida la Constitución política; decisiones de los agentes del poder o cualquier acto de los poderes del Estado; la organización del poder, esencia de un sistema de dominación: la organización del Estado y sus funciones, como la estructura de los tradicionales poderes Ejecutivo, Legislativo y Judicial, la adición de nuevas funciones o poderes; la creación de nuevas demarcaciones territoriales. Los hechos consumados pueden ser anulados por la decisión referendaria, esta la decisión puede ser anterior o posterior a una política de los titulares de la autoridad política.

La consulta al pueblo soberano no debería tener restricciones o asuntos vedados, o muy pocos. Es casi una obsesión evitar injerencias ciudadanas en asuntos que se reservan los gobernantes; por ejemplo, impuestos, políticas financieras y la distribución del gasto público, la disposición sobre la propiedad pública, ámbitos donde más se favorece a intereses privados; se 
exime de intervenciones el nombramiento o remoción de los funcionarios, los judiciales; por caso, los jueces pertenecen al mundo de la oscuridad, a la discrecionalidad. Gobernantes y legisladores se rehúsan a someter a escrutinio cómo usan sus facultades, consideran la Constitución y sus reformas como exclusividad del Estado. Los asuntos exceptuados de consulta son justamente esferas de conflicto planteados por los movimientos interesados en la democratización de las instituciones.

Las excepciones de materias de consulta o convocar o no a una consulta son opciones que se dirimen en la lucha de intereses; no todo asunto tiene una solución positiva, bien pueden reafirmar los intereses de las élites (el perdón a los servidores de la dictadura o a los corruptos, la expulsión de los migrantes extranjeros o la prohibición del aborto). Tácticamente, parecería mejor abstenerse de promoverla por temor a una regresión. Pero el cálculo pragmático no puede estar por encima de la formación de una cultura democrática; en el contexto mexicano son de interés nacional y local las consultas para poner límites a la contratación de deuda pública, la privatización de bienes nacionales y servicios públicos, las políticas de seguridad o ciertos tratados internacionales. En rigor, desde la perspectiva de la soberanía popular, no hay zonas vedadas a su intervención. Cualquiera que sea el resultado, la consulta confronta a las corrientes de la opinión pública evidenciando las opciones para su convivencia.

\section{TIPOLOGÍA DE LAS CONSULTAS}

La democracia directa ha especializado sus instrumentos de consulta a los electores en dos tipos, el plebiscito y el referéndum; en ambos, el cuerpo electoral, comunidad o sector, opina y decide, el pueblo legisla directamente. Se ha reservado el concepto de referéndum al ámbito de la legislación: aprobación o rechazo de una constitución, su reforma, abrogación, nuevas leyes o decretos. Lo mismo se aplica en las divisiones geopolíticas, en el nivel municipal es aplicable a los bandos de gobierno. Por su parte, el plebiscito se dedica a resolver decisiones políticas tomadas por cualquier órgano del Estado, o iniciativas provenientes directamente de los ciudadanos. En ambos casos, el pueblo dicta el sentido de la acción (Hamon, 2007). 
Para que la consulta sea auténtica, el resultado siempre ha de ser obligatorio, vinculante, para los poderes del Estado. El referéndum se llama obligatorio cuando es un requisito constitucional para dar validez a una decisión política; es el caso del referéndum constitucional; en muchos países es obligatorio someter a la aprobación del pueblo una nueva constitución elaborada por una asamblea constituyente, que no fue el caso de la aprobación de la Constitución de la Ciudad de México. El proceso de referéndum constitucional tiene tres momentos: la convocatoria a un congreso constituyente, la elección de los constituyentes y la aprobación del texto constitucional. Si se refiere a leyes secundarias, se le conoce como referéndum legislativo, una nueva ley o su enmienda.

Una mención especial merece la obligatoriedad de la consulta previa, libre e informada a las comunidades para realizar en sus territorios obras públicas o privadas. En este caso, son posibles tanto la convocatoria a los habitantes de un territorio como a un segmento de ellos con criterios de delimitación culturales y sociológicos. ${ }^{5}$

s La Relatora Especial de la Organización de Naciones Unidas sobre los Derechos de los Pueblos Indígenas, Victoria Tauli-Corpuz, afirmó que en México no se cumple con la consulta a los pueblos y comunidades indígenas que se ven afectados por legislaciones y proyectos de desarrollo que modifican su modo de vida y afectan los recursos naturales de su entorno. La consulta debe hacerse antes de aprobar dichas leyes y proyectos. La ausencia de legislación nacional o local no exime a los Estados de esta obligación con los pueblos indígenas, en cumplimiento de sus compromisos y obligaciones internacionales. Un ejemplo de violación a ese derecho ocurrió en la primera consulta en Juchitán, Oaxaca, respecto a un megaproyecto eólico impulsado por el gobierno en 20I4, aprovechando la llamada reforma energética. Se constató la falta de transparencia en la información, inadecuación cultural, violación al carácter previo de la consulta, indebida intervención de la empresa, falta de claridad y eficacia en los mecanismos de toma de decisiones, entre otros. (La jornada, 20I6, p. 22) Con el mismo motivo, la Comisión Nacional de Derechos humanos exhortó al Poder Ejecutivo Federal a presentar una iniciativa de ley sobre la consulta a los pueblos indígenas, pues hasta ahora persiste la violación a este derecho en la ejecución de diversos megaproyectos en el país. Deben garantizarse los derechos a la libre determinación, desarrollo sustentable, propiedad ancestral, biodiversidad e identidad cultural, entre otros. Otros casos de violaciones fueron el Acueducto Independencia que atraviesa siete estados, el cual vulneró los derechos del pueblo Wixárika en el Valle del Yaqui, Sonora. Otros ejemplos de violaciones han ocurrido en San Luis Potosí y el proyecto de presa La Parota en Guerrero, 
Cuando la decisión política no está condicionada a una consulta previa, se le denomina consulta voluntaria o facultativa; se recurre a ella cuando hay una necesidad. El plebiscito puede ser arbitral cuando su finalidad es resolver conflictos entre órganos del Estado, aunque es de suponer que el conflicto tenga un fondo trascendente para la sociedad, aunque con apariencia de conflicto entre poderes del Estado. El referéndum revocatorio se aplica para destituir del cargo a un representante electo; aquí el cuerpo electoral es el mismo que eligió al representante o gobernante: todo el país, un estado, un municipio o una circunscripción electoral para diputados y senadores.

Cuando el gobernante se arroga el papel de soberano no consulta, sino escucha; entonces, se habla del referéndum consultivo. Sirve para obtener una opinión indicativa, un consejo, pero no para aprobar o derogar leyes ni ninguna otra decisión puesto que no es vinculante. Es inadmisible que los gobernantes se opongan a la voluntad del pueblo expresada en un referéndum, aunque puede haber atenuantes circunstanciales. J. Ridao menciona una excepción: dejaría de ser vinculante si la ciudadanía se polariza en dos bandos iguales; en los demás casos, la obligatoriedad debería ser inexcusable. Si la autoridad no lo acata, incurre en una suerte de golpe de Estado institucional, con las consecuencias que pueda tener, pues el sujeto de la soberanía es el pueblo, él tiene la última palabra en los asuntos de Estado y debería ejecutarse inmediatamente (Ridao, 20I4, pp. 68-69).

\section{CONVOCANTES}

Están autorizados a convocar consultas los órganos del Estado y los ciudadanos mediante la iniciativa legislativa. En el primer caso, depende de la voluntad del Poder Ejecutivo y de los partidos políticos representados en el Legislativo; a veces, los regímenes autoritarios excluyen la iniciativa ciudadana. En el segundo, corresponde a los deseos de un movimiento de opinión pública que la solicita al Poder Legislativo.

Las consultas convocadas por gobiernos autoritarios y totalitarios tiene una connotación negativa por haber sido empleada para reafirmar plebisci-

y más casos donde la población fue perjudicada por proyectos mineros, hidráulicos o por la producción de alimentos transgénicos (Román, 20I6) 
tariamente al dictador, lo contrario de la revocación de mandato. Justamente para evitar que sea desnaturalizada su calidad ciudadana, no se ha permitido que sea una facultad exclusiva del jefe del Estado o de gobierno; tiene que ser una facultad de la representación nacional, del órgano representativo de la diversidad social, sin que en ello intervenga autorización alguna del gobierno, y puede también ser iniciativa del gobierno. La convocatoria en una parte del territorio o a una parte de los ciudadanos corresponde primero a los órganos legislativos estatales sin requerir de ninguna autorización. Esta precaución se justifica porque es frecuente que los Estados sean gobernados de manera dictatorial por un gobernador que de facto tiene en sus manos todos los poderes y la capacidad de impedir el ejercicio de derecho democrático a decidir. ${ }^{6}$

En espacios locales de la consulta (regiones, municipios y niveles submunicipales), la prioridad para convocar debe recaer en los ayuntamientos por ser órganos representativos potencialmente capaces de contrapesar a los caciques locales.

Lo más ventajoso, desde el punto de vista de la cultura democrática, es el derecho ciudadano de convocatoria, empleando el procedimiento de iniciativa legislativa popular, a condición de que los requisitos sean verdaderamente accesibles para presentarla y procesarla en el Legislativo, porque estimula la voluntad de una parte de la ciudadanía y activa la participación en los asuntos públicos. Una obstrucción frecuente es exigir cantidades elevadas de firmas de ciudadanos que avalen una iniciativa con el fin de dificultar su admisión a trámite.

${ }^{6}$ El artículo 92 de la Constitución española señala que la convocatoria es una facultad exclusiva del Estado a propuesta del presidente del gobierno, previamente autorizado por el Congreso de los Diputados, pero al final la autoriza el rey. Por tanto, cada una de estas instancias puede bloquear la convocatoria y anular el ejercicio del derecho. Además, el referéndum es admitido para la totalidad del país; los referendos locales tienen una calidad meramente consultiva. Esos argumentos se han utilizado en los años recientes para impedir el referéndum independentista de Cataluña (De Carreras, 20I4, p. 9I; Tajadura Tejada, 20I4, p. 2I6). 


\section{REVOCACIÓN DE MANDATO}

La revocación de mandato es un derecho ciudadano estatuido en muchos países, cuyo fin es contrarrestar el ejercicio arbitrario del poder por quienes lo ejercen gracias a una elección ciudadana. Se ejerce mediante referéndum contra los titulares de los poderes ejecutivos (en cualquier nivel territorial), así como a los integrantes del Poder Legislativo. Pero una acepción más amplia podría incluir a los titulares del Poder Judicial y en general a todos quienes dirigen cualquier organismo del Estado; se trata de un debate muy importante porque puede controlar al supremo poder conservador como es el Judicial, así como a los miembros de las burocracias ejecutivas designadas, quienes ejercen autoridad efectiva sobre los ciudadanos.

El referéndum revocatorio de mandato es un recurso de sanción y corrección que potencialmente tienen los ciudadanos no solo apartando a los funcionarios perjudiciales para la sociedad, sino también como medio disciplinario del ejercicio de la autoridad por el conjunto de quienes ejercen funciones en su nombre y representación. Castiga y disuade, pero también favorece la formación de consensos políticos, esclarece las corrientes de opinión ciudadanas y contribuye a afirmar el interés general o mayoritario en el ejercicio del poder del Estado.

La representatividad está ligada al mandato de los electores, quienes previamente eligen entre opciones partidarias, traducidas en forma de programas o plataformas electorales, de los cuales son portadores los elegidos; estos representan al mandante y actúan en su nombre; los electos asumen un compromiso con los electores y responsabilidades relativas al cargo. Están políticamente obligados a cumplir con el programa de campańa; de lo contrario, debe entenderse como renuncia al mandato y por consiguiente a la representación. El cumplimiento de la voluntad de los electores es exigible por ellos mismos sancionándolos con la destitución del cargo, mediante un procedimiento democrático llamado referéndum revocatorio de mandato; los mismos ciudadanos que eligieron a un representante votan por Sí o para No destituirlo.

La representatividad es intrínseca al programa político, expresa una orientación básica de la política por la que opta la mayoría de los electores, es determinante sobre las decisiones a tomar por los representantes. El incum- 
plimiento del mandato extingue el contrato social, equivale en el derecho civil a la pérdida de confianza. Es políticamente procedente por varias causas: incompetencia, uso indebido de funciones o abuso de poder.

Un método distinto es el juicio político donde los partidos en el Poder Legislativo son los que deciden quitarle la inmunidad al implicado y pueda ser procesado judicialmente, para lo cual debe haber causales, delitos y cargos. La revocación mediante juicio político es facultad del Poder Legislativo con independencia de los poderes Ejecutivo y Judicial.

Para actualizar el compromiso con los electores, hay otros medios complementarios para que los ciudadanos se informen y se expresen, entre ellos las asambleas ciudadanas y vecinales, foros, observatorios, contraloría social, cabildo abierto, rendición de cuentas y la consulta a los representados. Estos medios permiten dar realidad al juramento que hacen los elegidos en el momento de la investidura: de no cumplir con la representación, «que la nación se los demande». Por encima de resistencias conservadoras al reconocimiento de este derecho se sitúa el principio republicano de que la nación es soberana, es mandante, se sirve de comisionados, quienes están obligados a cumplir sus determinaciones. En ese principio se basa la confianza y el consentimiento de los gobernados hacia una autoridad conferida, que bien puede remplazar o confirmar.

Los partidarios de la monopolización del poder se rehúsan a aceptar que los electores mandaten a los representantes tanto como a la revocación, porque perderían la tradicional independencia de los representantes respecto a los representados. En el contexto mexicano, tal independencia no es una disquisición abstracta; forma parte de los mecanismos de monopolización del poder político que no corrige la elección periódica de representantes; más bien, tiende a reforzarse por varias vías. Una de ellas es la prolongación de la duración del cargo mediante la reelección inmediata de alcaldes y diputados; el nepotismo aporta una cuota a la monopolización del poder, fenómeno indicativo de la tendencia a conservar el poder en una minoría cada vez más cerrada; también contribuye el levantamiento de barreras de protección de la inamovilidad durante el periodo del cargo; la más debatida en la opinión pública es la inmunidad o fuero, asegura. En décadas recientes, la autonomía de los gobernantes ha garantizado la asociación entre poder y negocios, que 
complicaría la vigencia de la responsabilidad política de los representantes ante los representados.

Para hacer valer la supremacía del interés público, se han venido demandando la revocación de mandato y la eliminación del fuero Parece que ya se ha formado un consenso nacional respecto a la eliminación del fuero para todos los cargos de elección que bloquea su enjuiciamiento en cualquier momento por delitos que cometan, especialmente la práctica de usar el cargo público en beneficio privado. Por su parte, el referéndum revocatorio tiene más profundas implicaciones, hace sentir el peso de los ciudadanos sobre la clase política empleando un medio indiscutible, como es el sufragio efectivo.

El referéndum revocatorio, por ser un instrumento del derecho de soberanía, debe comprender a todos quienes dirigen los tres poderes del Estado: Ejecutivo, Legislativo y Judicial (desde los síndicos y regidores de los ayuntamientos hasta el presidente de la República, jueces y magistrados).7 El autogobierno judicial recuerda un pasado supuestamente desaparecido, como el fuero eclesiástico o el fuero militar, vive aún en la era de la privatización del Estado, actualiza su papel protector de la clase dominante. Su reconocimiento constitucional contribuiría a enderezar el predominio histórico del Poder Ejecutivo, tras el cual se encuentran intocables los poderosos altos funcionarios designados, los secretarios de Estado y sus equivalentes en las entidades federativas, la alta tecnocracia, los directivos de órganos colegiados de entidades descentralizadas o autónomas. En un régimen presidencialista, sin control parlamentario, no hay contrapeso mayor que el cuerpo electoral; el presidente de la República debería ser el primero en someterse al desafuero y a la revocación de mandato.

El referéndum revocatorio procede contra la autoridad electa, pero ¿cómo proceder contra los funcionarios designados por ella? La responsabilidad política recae en ambos sujetos: la autoridad que nombró y el funcionario subordinado cuya conducta se juzga, así en toda jerarquía de autoridad. La responsabilidad recae en primer término en la autoridad que nombra, luego entonces la revocación procede primero contra esa autoridad. Destituir a un

${ }^{7}$ La Constitución Política del Estado de Sinaloa, artículo I50, admite el derecho de los habitantes a «recusar el nombramiento de autoridades, hecho por el Ejecutivo, por el Supremo Tribunal de Justicia o por los Ayuntamientos» (Gamboa \& Ayala, 2006, pp. 23-24). 
funcionario designado técnicamente es problemático porque no operan los requisitos sobre qué parte de los electores tiene derecho a revocar, padrón, votación mínima, etcétera. El procedimiento tendría que ser más flexible que el exigido para el referéndum revocatorio de autoridades electas. Dos procedimientos son accesibles: una consulta o una iniciativa ciudadana destituyente ante el órgano legislativo que corresponda.

La consulta convocada por el órgano legislativo, según sea el funcionario municipal, estatal o nacional, a iniciativa de cierto número de ciudadanos, vota una cantidad mínima del padrón de la demarcación que corresponda, pongamos por caso uno por ciento; por ejemplo, de un padrón nacional de 80 millones, 800 mil votos; un porcentaje mayor en estados y más alto en municipios; el número de votos podría ser decreciente, según la posición jerárquica del funcionario.

Una vía más clara sería por iniciativa popular destituyente, apoyada en cierto número de firmas o adhesiones ciudadanas para obligar a que el Poder Legislativo destituya por mayoría simple. Este tipo de iniciativa seguiría un procedimiento semejante a la iniciativa popular legislativa, pero con requisitos menores. Las causas de la propuesta destituyente serían políticas, funcionales y penales, básicamente las que aquejan al país: abuso de autoridad, corrupción, ataques a los derechos humanos, económicos, sociales, culturales, incompetencia y faltas específicas en las respectivas esferas de competencia. En relación con la duración del cargo, no debería haber límites teniendo en cuenta que las autoridades electas nombran y remueven discrecionalmente.

Hay otros aspectos complementarios que son relevantes en cuanto a la monopolización del poder político a que nos hemos referido. Se observa la tendencia a nombrar altos funcionarios por una duración mayor a los seis años, los hay hasta por quince; una corrección a las reglas de procedimiento consistiría en aplicar el límite de duración igual que para todos los cargos de elección o no; ningún cargo debería durar un periodo mayor a seis años, lo mismo cargos judiciales o administrativos, que es el límite para los más importantes cargos de elección; mientras más largo sea el periodo, la iniciativa destituyente o el referéndum procedería en periodos más cortos a partir del primer tercio del periodo. 
El requisito de cantidad de avales de una iniciativa destituyente podría ser accesible, digamos, cien mil ciudadanos para un secretario de Estado o tal vez $0.5 \%$ de los inscritos en el padrón electoral de la demarcación. Es necesario prever las habituales manipulaciones de los políticos para entorpecer, postergar o archivar las iniciativas; si una iniciativa de origen ciudadano propuesta al Legislativo no es resuelta en el periodo de sesiones, se hace efectiva la destitución, un criterio del tipo afirmativa ficta.

Contra la revocación se arguye que podría provocar ingobernabilidad e inestabilidad política al ser utilizado en la lucha por el poder entre partidos, los políticos se amenazarían entre sí con la revocación. Otra causa de inestabilidad son las campañas que los monopolios de la comunicación emprenden para doblegar o derribar a quienes no se sometan a los grandes intereses privados. En todo caso, es inevitable la lucha por el poder; la destitución es uno de sus resultados con la diferencia de que la consulta es democrática. En el contexto mexicano, la inestabilidad no está relacionada con la revocación por la simple razón de que hasta hoy no ha sido permitida a la sociedad. La inconformidad se ha abierto paso de otro modo; hay una larga la historia de rebeliones populares municipales o contra gobernadores; al cerrar las vías democráticas, el régimen autoritario orilla a la violencia política. Por el contrario, la práctica de la revocación de mandato es congruente con el ejercicio legítimo del poder, ofrece una base consensuada para la estabilidad y la gobernabilidad.

Por lo general, políticos y funcionarios hacen carrera sin haber sido socialmente evaluados. Antes de recurrir a la revocación o destitución, debería practicarse la vigilancia del desempeño, la contraloría social generalizada, hace falta el control social sobre el desempeño de todas las autoridades y todas las instituciones del poder público, cuestión todavía ausente en el debate sobre la subordinación del poder político al interés público; más resonancia declarativa ha tenido la figura de la rendición de cuentas, que es un momento del proceso de control.

Un problema que no puede resolver la revocación es de carácter cuantitativo, cuando los numerosos políticos electos y designados se libran de la corrupción y abuso de poder que sufre el país, la solución ha de buscarse en la rebelión electoral. 


\section{OTROS INSTRUMENTOS DEMOCRATIZADORES}

Son congruentes con las formas de consulta al pueblo otras modalidades de formación y expresión de la opinión pública, pertenecen a los derechos de ciudadanía, pero no tienen el mismo alcance institucional, como asambleas y foros ciudadanos, el cabildo abierto y audiencias públicas, donde se relacionan directamente las autoridades con la ciudadanía; contribuyen a la cultura participativa sin formalidades las consultas telefónicas o electrónicas, encuestas, votaciones y adhesiones por iniciativa ciudadana (cita oculta para conservar el anonimato del autor).

\section{INICIATIVA LEGISLATIVA POPULAR}

No es estrictamente una consulta, sino el ejercicio del derecho de los ciudadanos a presentar iniciativas de ley o decretos, tratándolas en condiciones de igualdad en el procedimiento legislativo con las iniciativas de los partidos. La iniciativa popular de ley tiene sus propios requisitos, principalmente el aval de una cantidad mínima de ciudadanos registrados en el padrón electoral. En el supuesto de ser obstruida por los legisladores, la salida es llevarla a una consulta al pueblo. Esta forma participativa es más aceptada, pero no está exenta de obstrucciones por los gobernantes; por ejemplo, fijando una cantidad muy elevada de firmas de ciudadanos avalando el procedimiento.

La expresión de la opinión de los ciudadanos o miembros de un grupo específico adopta variados medios congruentes con la democratización de la vida política, como las elecciones primarias para elegir candidatos de los partidos políticos o las listas abiertas de candidatos. Igualmente, en instituciones y organizaciones sociales la jefatura autocrática es corregida mediante la dirección colegiada, concejos de delegados y restricciones a la reelección, entre otras. Todas estas formas no consultivas son compatibles con el método asambleario de deliberación entre ciudadanos.

Otras innovaciones ciudadanas vienen ensanchando los caminos de la democracia participativa en Latinoamérica, orientadas a la intervención directa de los miembros en la gestión de la vida comunitaria y en las tareas de gobierno, no solo entendida como colaboración, sino más exactamente como cogobierno y autogobierno; ejemplo de ello son el presupuesto parti- 
cipativo, la contraloría ciudadana, consejos de gestión y consejos comunales. A este campo pertenecen las policías comunitarias, el trabajo comunitario y las variadas formas de economía social y solidaria.

En suma, las demandas de mayores espacios de participación democrática son apremiantes para corregir las tendencias a la monopolización del poder por las élites partidarias, burocráticas y empresariales, para contender contra patologías como la violencia delincuencial, los abusos de empresas privadas contra el interés público, la corrupción y el ejercicio arbitrario del poder.

\section{EL SINUOSO CAMINO DE LA CONSULTA AL PUEBLO, SEGÚN EL ARTÍCULO 35 DE LA CONSTITUCIÓN POLÍTICA DE MÉXICO}

El artículo 35 de la CPEUM (2OI4) amplió los derechos del ciudadano en tres formas: el registro de candidatos independientes de los partidos (2012), votar en las consultas populares sobre temas de trascendencia nacional (2012) y la iniciativa legislativa popular (20I4). Para su aplicación, se emitió la Ley de Consulta Popular en 2014.

Parecería que hay una ampliación significativa de los derechos políticos ciudadanos, pero solo en apariencia. Desde su estreno en 2015 el objetivo democrático de las candidaturas independientes, "ciudadanas», está siendo tergiversado. ${ }^{8}$ A las consultas al pueblo se le ponen tales dificultades que las hacen difíciles de practicar. La iniciativa legislativa popular es una concesión a la «apertura democrática», derecho que siempre había estado monopolizado por el presidente, el gran legislador, y diputados y senadores al Congreso de la Unión (artículo 7 I constitucional). Carece de plazo límite para ser resuelta, tendrá que sortear el mecanismo tradicional empleado por los jefes de la mayoría de enviar al archivo muerto todo lo que sea contrario o irrelevante, según su agenda, o poner en acción su mayoría para votar en contra. Nominalmente, se habla de un progreso de los derechos ciudadanos

\footnotetext{
${ }^{8}$ No faltan candidatos ciudadanos ajenos a esa calidad: políticos que perdieron la candidatura interna en sus partidos políticos, líderes de organizaciones patronales y candidatos directos de empresas, otros son promovidos por el crimen organizado y organizaciones corporativas.
} 
porque aparecen esos conceptos en la legislación, pero distan mucho de estar al nivel de los avances internacionales. ${ }^{9}$

\section{CONVOCANTES}

Cabe destacar dos innovaciones ańadidas al artículo 35 de la CPEum: el derecho a iniciar leyes y a «votar en las consultas populares sobre temas de trascendencia nacional».

Tienen facultad para convocar las consultas tres actores: el presidente de la República, al menos el $33 \%$ de las cámaras de senadores y de diputados y los ciudadanos. La petición debe aprobarse por mayoría en ambas cámaras, excepto cuando la iniciativa de convocatoria provenga de los ciudadanos; en ese caso, no procede la aprobación por mayoría de las cámaras del Congreso de la Unión; en cambio, debe pasar por otros requisitos, donde aparecen los obstáculos.

${ }^{9}$ Los mecanismos de democracia directa han ganado un peso considerable en Latinoamérica; desde los años noventa del siglo xx se incorporaron o ampliaron estos mecanismos mediante reformas constitucionales, pero desde la primera década del siglo xxi se ha producido el $40 \%$ de las consultas realizadas en medio siglo. Yanina Welp (2009) sostiene que la orientación ideológica de los gobiernos «no aparece como una variable determinante», pues los han impulsado neoliberales tanto como partidarios de políticas redistributivas. Sin embargo, destacan en estos últimos Venezuela, Ecuador y Bolivia, donde se han incluido en las nuevas constituciones de 1999, 2008 y 2009, respectivamente, en especial la revocación de mandato.

Los requisitos para convocar el referéndum por los ciudadanos varían desde el $6 \%$ de firmas registradas en el padrón en Bolivia, el 8\% en Ecuador, el IO\% en Perú y el 20\% en Venezuela. El umbral de validez también es variable: en Perú y Bolivia debe contar con más del 50\% de votos, en Venezuela no se exige un quórum.

Para Welp, el referéndum está en tensión con la democracia representativa, no se complementan, sino que compiten, por sí solo no genera consenso, «que en América Latina la democracia directa ha servido para canalizar un enfrentamiento preexistente»; paradójicamente, en algunos casos consolida la democracia, pero a veces "puede contribuir a reforzar el espiral de la inestabilidad y la polarización de posiciones». Cabe agregar que los referendos en Venezuela, Ecuador y Bolivia, han contribuido a consolidar la democracia; derrotaron a las derechas, pero no se resignaron y continuaron en su política de desestabilización, particularmente en el caso de Venezuela (I36, I4I, I50). 
Primero, la «petición» de consulta ciudadana debe alcanzar «en un número equivalente, al menos, al dos por ciento de los inscritos en la lista nominal de electores». Este es el primer obstáculo para hacer lo más difícil posible su acceso. El requisito del 2\% de firmas de la lista nominal de electores es deliberadamente exagerada; supongamos que la lista contenga 80 millones de electores: el 2\% significa I millón 600 mil ciudadanos, poco menos que el umbral de la votación nacional para que los partidos conserven su registro.

En cambio, a la iniciativa legislativa popular se le fija como mínimo el respaldo de $0.13 \%$ de la lista nominal de electores. ${ }^{10}$ Una cifra no tan difícil de alcanzar, en 2014 alrededor de ir8 mil firmas de ciudadanos." ${ }^{\text {II }}$ le da un estatus menor a la iniciativa ciudadana para convocar a una consulta, porque es un derecho, no una mera "petición", expresión típica del oficialismo que considera al ciudadano como peticionario, no como sujeto de derechos. La iniciativa ciudadana para llevar a cabo una consulta debería tratarse como cualquier otra iniciativa legislativa ciudadana, incluyendo el requisito para ser presentada por el $0.13 \%$ mencionado.

La segunda dificultad proviene de requisitos adicionales, está condicionada por la voluntad de dos órganos del Estado: la Suprema Corte de Justicia de la Nación (scjN) y los consejeros "ciudadanos» del Instituto Nacional Electoral (INE). Cada uno de estos órganos puede manipular cómodamente la negación a la solicitud interpretando de manera discrecional los procedimientos, pues difícilmente podrían oponerse a una "petición» presidencial.

${ }^{10} \mathrm{El}$ artículo 7I constitucional, según la reforma de 20I2, otorga el derecho de iniciar leyes o decretos a los ciudadanos: «IV. A los ciudadanos en un número equivalente, por lo menos, al cero punto trece por ciento de la lista nominal de electores...». La ley reglamentaria determinará el trámite que deba darse a las iniciativas, ajustándose al marco constitucional: "Artículo 72. Todo proyecto de ley o decreto, cuya resolución no sea exclusiva de alguna de las Cámaras, se discutirá sucesivamente en ambas, observándose la ley del Congreso y sus reglamentos respectivos, sobre la forma, intervalos y modo de proceder en las discusiones y votaciones...». Aprobado por las dos Cámaras, se remite al Ejecutivo, quien, si no hace observaciones, lo publicará inmediatamente.

${ }^{\text {II }} \mathrm{El}$ 0.13\% le pareció una cantidad aún muy alta a la diputada del Movimiento Ciudadano, Nelly Vargas, ya que el O.I3\% equivalía entonces (febrero de 20I4) al respaldo de II8 mil ciudadanos, «un número difícil de cubrir incluso para los partidos políticos». Finalmente, el dictamen de la Comisión de Gobernación fue aprobado por 375 diputados a favor, 34 en contra y 3 abstenciones, incluyendo los votos del PRD (Garduño y Méndez, 20I4). 
El tercer obstáculo es la proporción mínima de los votantes para hacer vinculatoria la consulta. Dice el artículo 35: «Cuando la participación total corresponda, al menos al cuarenta por ciento de los ciudadanos inscritos en la lista nominal de electores el resultado será vinculatorio para los poderes Ejecutivo y Legislativo federales y para las autoridades competentes».

Se puede interpretar que dicha participación mínima es valedera para estados y municipios. La validez de la votación es fijada a partir de un umbral alto (40\%) que no existe para la elección de candidatos a cargos públicos, incluido el presidente de la República, para los cuales no hay un porcentaje mínimo; se gana obteniendo la mitad más uno de los votos sin importar la cantidad de votos emitidos. La experiencia internacional muestra que la votación en referendos es menor que la elección de candidatos, por lo que se han fijado umbrales del 30\%; además, en nuestro caso, hay que considerar la tendencia a aumentar el abstencionismo, razón adicional para que sea muy alto el umbral de 40 por ciento. Si de verdad hubiera la intención de alentar la cultura democrática mediante la participación ciudadana en las decisiones políticas, la cantidad mínima de votantes tendría que ser al menos la cantidad de votos obtenidos en la elección respectiva, con una tasa de participación igual a aquella elección.

\section{REVOCACIÓN DE MANDATO EN ESTADOS Y MUNICIPIOS}

En muchos países existe la revocación del mandato de autoridades como sanción política, poco frecuente, que hacen los ciudadanos contra quienes vulneren el interés público, así como para restablecer la legitimidad del poder. En el caso de México, el derecho de referéndum revocatorio no se ha incorporado a la Constitución federal; el régimen autoritario se protege, como lo muestran los siguientes ejemplos. En Chihuahua, la scjn declaró inconstitucional la reforma a la Constitución estatal de 1997 que incorporó la revocación de mandato. El supremo poder conservador, con el argumento de que la Constitución federal no prevé el mecanismo de revocación de mandato, invalidó la fracción 4I del artículo 30 de la Constitución de Yucatán, reformada en 20I2, que preveía la revocación de mandato de los funcionarios públicos elegidos, incluidos el gobernador y los diputados locales. De hecho, era una simulación porque hacía inaccesible ese derecho, fijaba el i75\%! de 
los inscritos en la lista nominal de electores para «solicitar» al Congreso una convocatoria; semejante cifra apenas para admitir la iniciativa ciudadana, no para el referéndum mismo. La SCJN sentenció que bastaba un procedimiento ordinario para fincar responsabilidades a quien no cumpliera las funciones para las que fue elegido, lo que significa negar el derecho ciudadano a revocar el mandato (La Jornada, 20I7, p. 9; La Jornada, 20I2, p. 37).

Precisamente porque ese órgano del Estado se arroga la posición de poder supremo que no recibe su legitimidad por el voto del pueblo, se hace necesaria la elección popular de los magistrados y jueces, como ya ocurre en Bolivia desde 20II; ni siquiera sabemos de un juicio político o de procedencia contra los magistrados.

El Congreso del Estado de Nuevo León aprobó (i9 de abril de 20i6) una Ley de Participación Ciudadana, que estuvo archivada durante doce ańos; en 2004 y 2008 la promovieron algunas organizaciones civiles, pero en 2016, habiendo alcanzado mayor capacidad organizativa, en mayor número se movilizaron para hacerla posible. La coyuntura era favorable porque el Congreso estatal gozaba de mayor autonomía frente a un gobernador «independiente» o no partidario (Nuncio, 2016, p. I9).

Lo más debatido de dicha Ley fue el derecho de revocar el mandato del gobernador, diputados locales y presidentes municipales, aunque bajo requisitos que mucho complican su ejercicio. El primer paso, en el caso de los alcaldes, es la solicitud de la consulta; para ello, los municipios se clasifican en tres niveles: en municipios con hasta 4 mil electores se requiere la firma de $20 \%$ de los registrados en la lista nominal; de 4 mil a 20 mil electores, el $15 \%$ de la lista nominal, en municipios con más de 20 mil electores se requiere el Io\% de firmas. Solicitar la convocatoria a referéndum no implica que la legislatura simplemente la apruebe, pero una vez aprobada el umbral de votos favorables a la revocación varía en cada nivel: en municipios con hasta 4 mil inscritos se requiere el 50\% de los votos; donde haya de 4 mil a 20 mil, $45 \%$; con más de 20 mil, $40 \%$ de votantes de la lista nominal. ${ }^{\text {I2 }}$

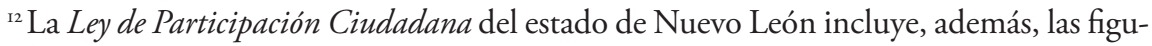
ras de iniciativa legislativa popular, audiencia pública, presupuesto participativo, contraloría social, consejos consultivos ciudadanos, asambleas y comités ciudadanos (Muníz, 20ı6) 
Para revocar se piden más votos que los que habitualmente obtienen los gobernantes elegidos; se ponen más obstáculos a los municipios pequeños, donde debería ser más accesible. Hipotéticamente, en las elecciones en un municipio pequeño, digamos con 4 mil electores, la votación total pudo ser del 50\%, 2 mil votos sumados todos los partidos y el candidato ganador obtuvo 500, pero la revocación exige mil. Un alcalde de un municipio medio (supongamos con 20 mil inscritos), con una participación del 50\% de votantes, pudo ganar la elección con 2 mil 500 votos, pero para revocarlo se piden 5 mil.

El movimiento cívico tendrá que hacer un gran esfuerzo para utilizar el instrumento revocatorio, aunque el movimiento ciudadano puede disponer de una diversidad de medios para el mismo fin.

\section{MATERIAS DE LA CONSULTA}

En línea con la legislación internacional al respecto, queda abierta la diversidad de materias de la consulta en el amplio marco de la frase asuntos de «trascendencia nacional». Se da por entendido que son trascendentes asuntos como una reforma constitucional, la aprobación de una nueva constitución o una determinada política; por ejemplo, someter al pueblo la decisión sobre la privatización energética. ${ }^{13}$ Sin embargo, la trascendencia es susceptible de interpretaciones, no es tan universal como pareciera.

${ }^{13}$ El senador del Partido del Trabajo, Manuel Bartlet, el jurista Jaime Cárdenas y otras personas, impugnaron la reforma constitucional en materia energética por ser contraria a la misma Constitución. (Ballinas y Becerril, 20I4). Puesto que ya había sido por la mayoría de los legisladores del Partido Revolucionario Institucional, los opositores intentaron someterla a una consulta nacional. (Méndez, 20I4). Miembros de la fracción parlamentaria del Partido de la Revolución Democrática sostuvieron que la mayoría trataba de impedir el referéndum; en cambio, ellos proponían que el referéndum se realizara el mismo día de las elecciones federales de junio de 20I5; finalmente, su propuesta fue desechada, pero el PRD presentó a la Suprema Corte I.6 millones de firmas avalando la consulta popular. (Garduño y Méndez, 20I4). De nada valió. El 3I de octubre de 2014 la Suprema Corte declaró improcedente la consulta sobre la reforma energética propuesta por los partidos Movimiento de Regeneración Nacional y PRD, porque tocaba el tema del ingreso-gasto del Estado, el cual no puede ser objeto de consulta. (Ballinas, 20I4). Con esta decisión cerró el paso a la expresión de la voluntad popular que seguramente sería adversa al propósito (Aranda, 20I4). 
Según el artículo 35, no serían asuntos de trascendencia nacional ciertos ámbitos del diseño institucional:

3o. No podrán ser objeto de consulta popular la restricción de los derechos humanos reconocidos por esta Constitución; los principios consagrados en el artículo 40 de la misma; la materia electoral; los ingresos y gastos del Estado; la seguridad nacional y la organización, funcionamiento y disciplina de la Fuerza Armada permanente.

Le han puesto límites al principio republicano por excelencia, según el cual el pueblo soberano está por encima del Estado institucional; al soberano corresponde decidir sobre cualquier asunto, sobre todo respecto a las funciones del Estado, pero resulta que el bloque en el poder le pone límites, una esfera que se reserva; además, la $S$ CJN tiene la facultad de interpretar que un asunto incurre en las prohibiciones.

\section{PROCEDIMIENTO}

Las consultas por iniciativa ciudadana, a diferencia de las propuestas por los integrantes de las dos Cámaras del Congreso de la Unión, tienen que pasar por dos filtros: «La Suprema Corte de Justicia de la Nación resolverá, previo a la convocatoria que realice el Congreso de la Unión, sobre la constitucionalidad de la materia de la consulta»; el segundo (apartado cuarto) asigna al INE la verificación del requisito del aval de $2 \%$ de electores y «la organización, desarrollo, cómputo y declaración de resultados».

El procedimiento para los partidos es menos complicado (Ley de Consultas Populares, artículos 7, 28, 33): (I) la iniciativa es presentada por una tercera parte de los legisladores en cualquiera de las Cámaras; (2) el dictamen de la petición debe ser aprobada por mayoría en cada Cámara; (3) la Cámara

Según una encuesta de Parametría, el 72\% de los entrevistados declaró su disposición a participar en una consulta sobre la reforma energética, contra la negativa del 25 por ciento. Asimismo, el 71\% participaría en una consulta sobre impuestos, 70\% sobre el incremento al salario mínimo, 71\% sobre la despenalización del aborto, 66\% sobre áreas en las que debe gastar el gobierno, 63\% sobre la disminución del gasto público, 59\% sobre reformas electorales y 49\% sobre legalización de la mariguana (Parametría, 20I4). 
revisora envía la petición y la propuesta de pregunta (nótese que restringe a una sola pregunta) a la SCJN para que resuelva sobre la constitucionalidad de la materia; (4) si es positiva la resolución, el Congreso expide la convocatoria.

Restringir a una sola pregunta es otro exceso. En muchos países es posible plantear varias, aunque no estén relacionadas; una pregunta puede tener variantes, lo cual implica más de una pregunta. No hay ninguna razón para restringir el número de preguntas, a menos que la intención sea minimizar tal derecho.

En cambio, cuando la "petición» (que no es iniciativa) es presentada por ciudadanos se sigue el siguiente procedimiento: (I) el presidente de la Mesa Directiva de la Cámara que corresponda solicita al INE verifique el aval firmado de $2 \%$ de los inscritos en la lista nominal de electores; (2) si cumple este requisito, el presidente de la Mesa Directiva envía la petición a la Suprema Corte, junto con la propuesta de pregunta de los peticionarios para que resuelva sobre: (I) la constitucionalidad de la materia y, (2) que la pregunta derive de dicha materia, que no sea tendenciosa, sin juicios de valor, lenguaje neutro, sencillo y comprensible y produzca una respuesta categórica positiva o negativa. Todo esto es normal, pero el colmo es que se permite a la Corte modificar la pregunta para que sea congruente con la materia, en vez de hacer la observación a los ciudadanos que la promueven; (3) si la Corte aprueba la constitucionalidad y la pregunta, el Congreso emite la Convocatoria y la notifica al InE. Este, a su vez, verifica que los nombres de quienes hayan suscrito la consulta popular aparezcan en la lista nominal de electores, la autenticidad de las firmas y que sumen al menos $2 \%$ de dicha lista.

La Ley de Consultas Populares añade una última barrera: introduce la caducidad del resultado. En el supuesto de llevarse a cabo la votación y de haber alcanzado al menos 40\% de participación de la lista nominal de electores, el resultado de la consulta será vinculatorio, pero «tendrá efectos durante los tres ańos siguientes» (Art. 64). Lo que decida el soberano caduca a los tres años, lo que convenga al bloque en el poder es intemporal. La consulta se hará el mismo día de la elección federal (artículo 35 constitucional), es decir, cada tres años, una consulta cada tres años sin ninguna consideración de las necesidades. 


\section{SEPARACIÓN DEL CARGO SIN PARTICIPACIÓN CIUDADANA}

El control institucional interno es taimado porque está determinado por el juego político. Del lado institucional existen tres mecanismos parlamentarios que terminan con el mandato del gobernante: (I) el juicio de procedencia, (2) declaración de desaparición de poderes dictada por el Senado en el caso de gobernadores y por el Legislativo estatal en los ayuntamientos (González, I987; Gamboa \& Ayala, 2006); (3) el juicio político, facultad de las cámaras de diputados y senadores. ${ }^{\mathrm{I}} \mathrm{Su}$ estado es latente hasta que la democracia los llame a la vida. Lo mismo se puede decir de la Secretaría de la Función Pública o del Sistema Nacional contra la Corrupción, que no han jugado más que un papel legitimador. La Contraloría Superior de la Federación, órgano de la Cámara de Diputados, cumple con investigar la corrupción, pero no tiene correspondencia con los tribunales. Al autocontrol administrativo le ha faltado lo principal, voluntad política.

$\mathrm{Al}$ control interno no le faltan delitos que perseguir, son los mismos que motivan la revocación de mandato por los ciudadanos. Respecto al juicio de responsabilidad y el juicio político, la Constitución de la República enumera las causales en los artículos I08, I09 y IIO. Los delitos son graves: violaciones a la Constitución, enriquecimiento ilícito, manejo indebido de recursos públicos, asociación delictuosa entre funcionarios e intereses privados, entre otros. No termina ahí el catálogo de vulneraciones al interés público.

${ }^{\mathrm{I} 4}$ En la Cámara de Diputados hay varios filtros para emprender un juicio político: la solicitud hecha por los partidos se presenta a la Secretaría General de la Cámara; esta la envía a la Subcomisión de Examen Previo; si su presidente lo autoriza, la remite a la Comisión Instructora, integrada por las comisiones de Justicia y Gobernación. (Garduño, 20I6). El control de esas instancias obviamente lo tiene el PRI, celoso protector de la impunidad. De hecho, nunca se tramitan, desde 2003 no se activa la Subcomisión; de esa fecha hasta marzo de 2016 había más de 337 solicitudes congeladas. (Méndez, 2016). La legislatura instalada en 2015 y hasta abril de 2016 no había integrado la Subcomisión de Examen Previo, instancia encargada de presentar los casos ante el pleno. (Méndez y Garduño, 20I6). Por su parte, el Poder Judicial de la Federación apremió a las comisiones de Gobernación y Justicia de la Cámara de Diputados a integrarla, o se procedería a la separación de cargo de las autoridades contumaces y serían consignadas por desacato. (Méndez y Garduño, 20I6, p. 3). En febrero de 2017 informó que la lista llegaba a 36r casos, de los cuales desechó i67 y le seguirían otras (Méndez y Garduño, 20I7). 
La Ley Federal de Responsabilidades de los Servidores Públicos enumera las siguientes causas de enjuiciamiento: ataque a las instituciones democráticas; ataque a la forma de gobierno republicano, representativo, federal; violaciones graves y sistemáticas a las garantías individuales o sociales; ataque a la libertad de sufragio; usurpación de atribuciones, perjuicio grave a la Federación, a uno o más estados o de la sociedad, o motive un trastorno en el funcionamiento normal de las instituciones, $\mathrm{u}$ omisiones graves a lo anterior; violaciones sistemáticas o graves a los planes, programas y presupuestos de la administración pública federal. Sanciona a los miembros y directivos de los órganos del Estado con la remoción o inhabilitación para ocupar cargos públicos por un periodo determinado (Diario Oficial de la Federación, 1982). El saneamiento de la administración pública reclama mucho más; los delitos graves contra el interés público y el interés nacional deben calificarse como imprescriptibles y la inhabilitación como definitiva. En la renuncia o destitución los ciudadanos no intervienen en absoluto.

\section{UN DIFICULTOSO AVANCE DE LA DEMOCRACIA DIRECTA EN EL ENTONCES DISTRITO FEDERAL}

La institucionalización de la democracia participativa en la Ciudad de México ha seguido un camino desigual; por un lado, una intensa demanda ciudadana, pero dispersa e inconsistente; por otro, la muy ensayada política del bloque en el poder de simular cierta democratización y al mismo tiempo interponiendo obstáculos a su realización.

El Estatuto de Gobierno del Distrito Federal (EGDF), aprobado por el Congreso de la Unión en 1994, reconoció vagamente la iniciativa popular y el plebiscito, pero dejó el resto de los instrumentos de participación ciudadana a la reglamentación dentro de la Ley de Participación Ciudadana del Distrito Federal (LPCDF). La reforma de diciembre de 1997 al Estatuto de Gobierno no mejoró sustancialmente los derechos de democracia semidirecta porque era una cuestión de principio negarle la autonomía de la Ciudad. Fue hasta el ańo 2000 cuando el partido gobernante concedió a la Asamblea Legislativa la facultad de legislar en materia de referéndum, plebiscito e 
iniciativa popular, que antes se reservaban al Congreso federal (Hernández \& Fernández, 20I3, pp. 6-9, II-I2).

Desde 1997 se estatuyó el derecho al plebiscito. El Estatuto decía:

[...] a través del plebiscito, el Jefe de Gobierno del Distrito Federal podrá consultar a los electores para que expresen su aprobación o rechazo previo a actos o decisiones del mismo que a su juicio sean trascendentes para la vida pública del Distrito Federal (Art. 68).

La reforma de 20 o simplemente repitió este texto. El Jefe de Gobierno conserva la facultad de convocatoria, a la iniciativa ciudadana se le redujo el umbral para solicitarlo de 0.5 a $0.4 \%$ de la lista nominal de electores; finalmente, cuando son los órganos de representación social los convocantes las cuotas fueron accesibles: el IO\% de los Comités Ciudadanos o al menos 8 de los I6 Consejos Delegacionales.

La Asamblea de Representantes del Distrito Federal expidió en 1995 la primera Ley de Participación Ciudadana (LPCDF), reformada en 2004, reconociendo las figuras de plebiscito, referéndum e iniciativa ciudadana. Los requisitos eran óptimos; para solicitarlos, establecía un mínimo de adhesiones de por lo menos el 0.5\% del padrón electoral de la elección más reciente. Posteriormente, la reforma de 2010 admitió el carácter vinculatorio del plebiscito cuando la votación alcance más de un tercio del padrón electoral y así permaneció en la reforma de 2013. En cambio, el referéndum continuó sin ser vinculante.

El único caso significativo de una convocatoria ocurrió en 2002 por iniciativa del entonces Jefe de Gobierno, Andrés Manuel López Obrador, quien promovió un plebiscito para que la ciudadanía se pronunciara sobre la construcción de un segundo piso al periférico. Los siguientes Jefes de Gobierno se abstuvieron de acudir a la democracia plebiscitaria; desde entonces, se limitaron a las consultas ciudadanas sabiendo que no tienen carácter vinculante.

La Ley de Participación Ciudadana (LPC) vulneró la autonomía ciudadana al darle a la Asamblea la facultad de modificar la pregunta sometida a referéndum; los diputados de la Asamblea Legislativa podían aprobar, modificar o rechazar la convocatoria ciudadana, aunque se hubieran satisfecho los 
requisitos y el Instituto Electoral de la ciudad hubiera certificado su cumplimiento. Los requisitos a cubrir para el plebiscito y el referéndum eran los mismos: la solicitud requería la indicación precisa de la ley o decreto, o el artículo que se proponía someter a referéndum, así como la exposición de razones que la motiven, los ciudadanos deberían reunir firmas por al menos el $0.4 \%$ de la lista nominal de electores o, indirectamente, el Io\% de los Comités Ciudadanos u ocho de los I6 Consejos Delegacionales.

Un examen de la cuestión elaborado por Héctor Hernández y Luis F. Fernández pone en evidencia los defectos de la legislación y concluyen con propuestas de consideración; propusieron corregir el diseño con el fin de impedir de dos maneras la discrecionalidad del Jefe de Gobierno y de la Asamblea: transferir la facultad de aprobar la solicitud de referéndum al órgano electoral y la obligatoriedad de la consulta en determinadas cuestiones y decisiones del gobierno. Respecto al referéndum, critican que se le haya quitado la sustancia al darle un carácter meramente consultivo; por tanto, la solución está en otorgar el carácter vinculatorio de los resultados del referéndum.

También la iniciativa legislativa popular era un derecho coartado, la Asamblea Legislativa la sometería al procedimiento ordinario, debería pasar por una comisión especial a la que se le dio el poder de aceptarla o rechazarla; por consiguiente, no se garantizaba que la propuesta se llevara a cabo. Teóricamente, con la iniciativa popular se rompería la exclusividad de los diputados de iniciar leyes ante la Asamblea de Representantes (Hernández \& Fernández, 20I3, pp. I3-I5).

Tal vez por las restricciones de la legislación anterior a la Constitución de la Ciudad a la participación ciudadana en la toma de decisiones, los tres instrumentos de democracia participativa fueron desdeñados. Según Hernández y Fernández, autores del estudio mencionado, la iniciativa popular no «tiene antecedentes en el Distrito Federal, pues no ha sido presentada iniciativa alguna por este medio desde que fue regulada en la reforma de la LPCDF de 20IO». Aun cuando la ciudadanía tiene la posibilidad de exigir que se lleve a cabo un plebiscito, no se ha realizado ninguno por iniciativa ciudadana desde su creación. A pesar del establecimiento del referéndum desde 2004, no se ha presentado uno solo desde esa fecha. En ninguna de las reformas mencionadas se admite el referéndum revocatorio. 
En el contexto nacional, poco se ha avanzado en cuanto a la democracia participativa, no solo en la letra de la ley, sino sobre todo en el ejercicio efectivo por la sociedad. En varias constituciones estatales, como Baja California, Oaxaca, Guerrero, Zacatecas y Jalisco, se reconocen los derechos ciudadanos a participar en los procesos de consulta popular, referéndum, plebiscito, iniciativa legislativa popular; la revocación de mandato en raros casos; se prefieren la audiencia pública, el cabildo abierto y consejos consultivos (Gamboa \& Ayala, 20I6, pp. 20, 27, 34).

En el ámbito municipal, por lo general se ignoran estos derechos; según un estudio de la normatividad municipal realizado por el grupo Participando por México, la mayoría de los municipios no incorporan los mecanismos de participación ciudadana en su normatividad o no la han actualizado en más de diez años, pese a su necesidad para estructurar su administración municipal, para regular las relaciones con sus ciudadanos, para establecer los criterios y principios para la provisión de bienes y servicios públicos en sus municipios y sus localidades. El estudio concluye que «no es posible asegurar que estos mecanismos hayan sido utilizados por ciudadanos o impulsados por la autoridad». ${ }^{\text {is }}$

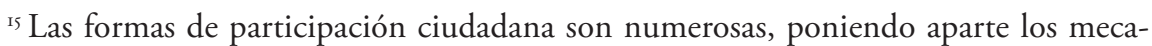
nismos de relación de los gobiernos con la ciudadanía. En un estudio hecho en 2015 por la asociación Participando por México sobre la existencia en los municipios del país de mecanismos de participación formalizados, obtuvo información de 432 sobre 2456 municipios. De ellos, cuentan en promedio 5.4 mecanismos por municipio. En el grupo de 432, el $67.6 \%$ fueron implementados entre 2013 y 20I5, pero en ese lapso la proporción de municipios en el país que no cuentan con instrumentos de participación ciudadana aumentó del $26 \%$ al 3 I por ciento. Los mecanismos de participación ciudadana (MPC) que aparecen con mayor frecuencia en la normatividad municipal son la Consulta Popular (I6\% del total), los Consejos de Participación Social 15\%, consejos de planificación municipal (I3\%, iniciativa popular $11 \%$, referéndum $9 \%$ y plebiscito 9 por ciento. Los municipios rurales con menos de Io mil habitantes cuentan más con mecanismos de democracia deliberativa y menos de democracia plebiscitaria; por el contrario, los municipios con mayor número de habitantes cuentan con más mecanismos de consulta (Participando por México, 20ı6, pp. 5, I6-I7, 2I, 24, 43-44). 


\section{LA CONSULTA AL PUEBLO EN LA CONSTITUCIÓN DE LA CIUDAD DE MÉXICO}

La nueva Constitución Política de la Ciudad de México (СРСм) retoma derechos ciudadanos contenidos en la legislación precedente, pero subsana muchas de sus limitaciones; aún quedan deficiencias que complican su aplicación; debemos esperar que se corrijan conforme progrese la democratización. La definición general de la democracia directa abre posibilidades que podrán concretarse en las leyes secundarias.

Respecto a los derechos de consulta al pueblo, lo esencial está contenido en el artículo 25 de la СРСМ. El apartado A estatuye el interés general y la gestión estatal como espacios de la intervención ciudadana. A continuación, los resumimos.

I) Las y los ciudadanos tienen el derecho y el deber de participar en la resolución de problemas y temas de interés general y en el mejoramiento de las normas que regulan las relaciones en la comunidad, a través de los mecanismos de democracia directa y participativa reconocidos por esta Constitución. Dichos mecanismos se podrán apoyar en el uso intensivo de las tecnologías de información y la comunicación.

2) Las autoridades de la Ciudad garantizarán la democracia participativa, entendida como el derecho de las personas a incidir, individual o colectivamente, en las decisiones públicas y en la formulación, ejecución, evaluación y control del ejercicio de la función pública.

El texto final recogió los mismos términos del Proyecto de Constitución presentado por el jefe de gobierno de la Ciudad a la Asamblea Constituyente (Art. 30.I; Proyecto de Constitución Política de la Ciudad de México, 20I6). El documento abarca varios temas relacionados con la democracia participativa y otros derechos, entre ellos los humanos, sociales, políticos, económicos, culturales y ambientales. En este escrito se aborda solamente lo relativo a la consulta al pueblo.

El derecho de participación en asuntos de «interés general» es un enunciado que requiere añadir especificaciones; el concepto de interés público alude a 
los asuntos públicos en los ámbitos social y estatal; el segundo señala al Estado como objeto de la participación. El propósito es la supremacía del interés público sobre el interés privado, determinante para enfrentar los grandes problemas de la corrupción y el abuso de poder (Art. 28, fracciones V y viI).

El proyecto entiende por democracia «directa» el derecho de consultar al pueblo, pero esa es solo una de sus dimensiones. La democracia directa es una noción compleja, pues comprende un conjunto de formas de autogestión de los ciudadanos; por ejemplo, los emprendimientos regidos por el principio cooperativo o el comunitario; se caracterizan por el autogobierno de los miembros del grupo, fusiona la decisión y la acción, la autonomía, así como a un sistema de valores. Por esa razón, es más apropiado designar las formas de consulta como democracia semidirecta, pero aquí no entramos a discutirlo y seguimos empleando el término directa.

La definición de democracia participativa gira en torno al concepto de «incidir», su ámbito son las decisiones públicas en sus diferentes etapas: en la toma de decisiones, formulación, ejecución, evaluación y control del ejercicio de la función pública. Por separado se menciona la planificación participativa (Arts. 26. A. 2 y 4, y B. I). El reconocimiento de esas siete modalidades pone a disposición de la Ciudad el desarrollo de las instituciones sociales participativas en consonancia con las legislaciones latinoamericanas más avanzadas, como la Ley de Participación y Control Social de Bolivia, ley 850 de las veedurías ciudadanas en Colombia, la Ley de Consejos Comunales en Venezuela y los consejos de políticas públicas en Brasil, entre otras.

\section{INICIATIVA LEGISLATIVA CIUDADANA}

La Constitución de la Ciudad reconoce el derecho ciudadano a iniciar leyes, decretos y reformas a la Constitución ante el Congreso de la Ciudad. El proyecto Mancera decía: siempre que cuenten con «las firmas de al menos $0.25 \%$ de los inscritos en la lista nominal de electores de la ciudad» (Art. 30. B.), un porcentaje alto comparándolo con el artículo 35 de la Constitución federal, que lo fija en 0.13\% del electorado nacional para la misma iniciativa legislativa. Denotaba la intención de hacerla menos accesible. La Constitución aprobada rectifica ese error reduciendo el número de firmas a 0.13\% 
de la lista nominal de electores de la Ciudad. Las iniciativas «preferentes» deberán contar con el $0.25 \%$ de dichas firmas. Admitida la iniciativa, los proponentes pueden incorporarse a la discusión legislativa. En el mismo artículo, la Constitución establece el derecho ciudadano a proponer modificaciones a las iniciativas legislativas y a que sean tomadas en cuenta en el dictamen (Art. 25. A, B.; esto se repite en el Art. 30. e).

\section{REFERÉNDUM Y PLEBISCITO}

La Constitución de la Ciudad reconoce las tres formas características de la democracia «directa»: el referéndum constitucional, el plebiscito y las consultas, estas últimas clasificadas como ciudadanas y populares.

El referéndum constitucional es más bien un adorno porque desde el Proyecto presentado por Miguel Ángel Mancera se descartó el referéndum que debió aplicarse para la aprobación por el electorado de la totalidad de la Constitución. Recordemos que el proceso de conformación de una Asamblea Constituyente fue diseñado para que los ciudadanos intervinieran lo menos posible en su conformación, solo $28 \%$ de los ciudadanos votó en las elecciones de 60 constituyentes, los 40 restantes fueron designados por grupos institucionales. Un desaire semejante pudo haberse reparado si el texto aprobado por los constituyentes se hubiera sometido a referéndum. Se privaron de un soporte de la legitimidad y con ese acto anularon el referéndum constitucional.

Ateniéndose a la letra, el referéndum se aplica a reformas, no a las leyes completas. El texto dice: la Constitución de la Ciudad «reconoce el derecho ciudadano a aprobar mediante referéndum las reformas a esta Constitución» y demás disposiciones normativas, a solicitud del $0.4 \%$ de los inscritos en la lista nominal de electores (Art. 25. C. I.). Por su parte, el plebiscito se aplica para decisiones políticas del Jefe de Gobierno.

Se establece el plebiscito como derecho de los ciudadanos «a ser consultados [...] para aprobar o rechazar decisiones públicas que sean competencia del Poder Ejecutivo de la Ciudad, también a solicitud del $0.4 \%$ de los inscritos en la lista nominal de electores de la Ciudad» (Art. 25. D.I). La 
misma redacción aparece en el Proyecto encargado por Mancera a un grupo (Art. 30. C y D, I, 2, 5).

De este modo, se sustrae de la decisión política ciudadana al Poder Judicial (los actos del Legislativo son leyes), no solo en sus decisiones concretas, sino en su carácter de instituciones del Estado, cuyo diseño forma parte de la Constitución; por ejemplo, la elección popular de magistrados.

Mencionamos que el artículo 35 constitucional fija un mínimo exagerado para la "petición» de consulta, al menos $2 \%$ de la lista nominal de electores; en cambio, algunos partidos propusieron una cota más razonable: $0.25 \% \mathrm{o}$ 0.13\%; finalmente, la Constitución dejó la cota de 0.40\% (Art. 25. C).

Un auténtico movimiento ciudadano tendrá que esforzarse por contar con un amplio aval de la ciudadanía a una propuesta de consulta, pero teniendo en cuenta una larga historia de despolitización y pasividad inducida; lo más conveniente para la democracia participativa es poner un umbral bajo tanto para la Ciudad como para las alcaldías y demarcaciones territoriales más pequeńas.

\section{REFERÉNDUM REVOCATORIO DE MANDATO}

Antes de la reforma constitucional que erigió a la Ciudad de México (CDMx) en entidad federativa, por una tradición autoritaria, se había negado a los ciudadanos de la Ciudad el derecho a revocar a los funcionarios elegidos; era el Senado el que podía remover al Jefe de Gobierno, mientras la Asamblea Legislativa podía remover a los Jefes Delegacionales. Con la nueva Constitución es posible destituir a todos los representantes electos: Jefe de Gobierno, diputados al Congreso de la Ciudad, alcaldes y concejales. ${ }^{16}$ El artículo 25 fue aprobado por 65 constituyentes contra 23. Parecería natural que la revocación se reconociera como un derecho de soberanía de los habitantes de la Ciudad de México, entidad federativa. Sin embargo, se topa con la exclusión de este derecho en el artículo 35 de la Constitución de la República. Durante

${ }^{16}$ En varias constituciones de los estados de la federación ya se establecía la revocación de todos los servidores públicos de elección popular, incluyendo al gobernador, como en Baja California, Oaxaca, Jalisco, Guerrero y Sinaloa (Gamboa y Ayala, 20ı6, pp. IO-32) 
las cuatro últimas legislaturas federales, la mayoría oficialista se ha negado a aprobar las iniciativas en este sentido, una muestra más de la persistencia del régimen autoritario.

En la Constitución de la Ciudad no se explicitan los motivos que justifican la aplicación del referéndum que podrían ser, en primer lugar, el abuso de poder relacionado directamente con la pérdida de legitimidad y sus manifestaciones: violaciones a la Constitución, actos de corrupción, perjuicio a la hacienda pública, ineficiencia, violación a los derechos humanos, faltas administrativas graves y el incumplimiento de los programas ofrecidos en las campañas electorales. En Oaxaca, la Constitución precisa que el gobernador es revocable por delitos de lesa humanidad, lo que no sirvió para enjuiciar los crímenes del exgobernador Ulises Ruiz.

En su defecto, se pueden invocar las motivaciones que enumera la Constitución en el Capítulo II, de responsabilidades. Tienen responsabilidad política quienes ocupen cargos de elección popular y otros servidores públicos, «serán sujetos de juicio político por violaciones graves a esta Constitución» y «por el manejo indebido de fondos y recursos públicos de la Ciudad» (Art. 65.I). Cabe aclarar que el juicio político es una función del órgano legislativo, no de los ciudadanos, es un procedimiento distinto al referéndum revocatorio.

La referencia a violaciones graves a la Constitución se vincula con la responsabilidad penal por los «delitos que cometan los servidores públicos durante el tiempo de su encargo». Se relaciona también con las faltas administrativas (Art. 64.I.) y con la responsabilidad patrimonial cometida «por acción u omisión, dolo, negligencia o mala fe» (Art. 67.2.)

Todo esto justifica también el referéndum en contra de todos los servidores públicos; además, hay una alusión directa a los representantes elegidos: «nadie goza de fuero» (Art. 66.I.). Así pues, los tribunales pueden proceder directamente sin el intermedio del juicio político.

Si todos los servidores públicos elegidos pueden ser enjuiciados penal o administrativamente, eso basta para justificar la revocación de los altos funcionarios no electos, tanto en el conjunto de la Ciudad como en las demarcaciones y unidades territoriales, y en la función judicial. Tratándose de una autoridad delegada por un funcionario electo (jefe de gobierno o alcalde), se puede argumentar que todas las culpas de los subordinados 
recaen en la autoridad que los nombró; la responsabilidad individual ya está contenida en la revocación de la autoridad electa y no necesita mayor agregado; el problema surge cuando la autoridad es un órgano; por ejemplo, el Poder Legislativo o un órgano colegiado. La solución está en someter a la voluntad ciudadana todos los cargos de autoridad. Mientras no se reconozca esta ampliación del derecho de soberanía a revocar, el recurso queda trunco.

Son dos los requisitos que establece la Constitución para que proceda el referéndum revocatorio: (I) «La consulta para revocación del mandato solo procederá una vez, cuando haya transcurrido al menos la mitad de la duración del cargo de representación popular de que se trate», y (2) «a) Cuando así lo demande al menos el diez por ciento de las personas inscritas en la lista nominal de electores del ámbito respectivo» (Constitución de la Ciudad de México, Art. 25.G.I., Proyecto, art. 30. F). El primero es razonable, pero el segundo es alto; el Io\% equivaldría, supongamos, de un listado nominal de electores de siete millones, a 700 mil firmas tan solo para solicitarla.

El referéndum revocatorio es una variante del concepto de referéndum; para ser congruente, debería ser tratado como los demás tipos, es decir, con el aval de $0.4 \%$ de adherentes, como lo propone el Proyecto oficial o, todavía mejor, el $0.25 \%$ del listado nominal establecido para la iniciativa legislativa popular. El elevado monto equivale a una obstrucción del derecho ciudadano, movida por el celo de intocabilidad de la clase política.

En general, para el referéndum y el plebiscito los resultados serán vinculantes cuando la participación sea de al menos la tercera parte de los inscritos en el listado nominal del ámbito respectivo. En cambio, para las consultas ciudadanas en las alcaldías el umbral de participación quedó en $15 \%$, tal vez porque los «constituyentes» pensaron que las consecuencias serán focalizadas y que la pequeña escala del problema no altera la estabilidad del conjunto de los cargos. En los espacios locales no sería difícil alcanzar dicho I5\%; por tanto, a las poblaciones locales se les abre un amplio horizonte de control sobre los gobernantes locales.

Un tercio de participación en las urnas como mínimo para que el resultado sea vinculatorio es mejor que el 40\% establecido en el artículo 35 constitucional, pero un $30 \%$ sería más estimulante para la democracia participativa en la Ciudad como un todo, y $25 \%$ en las demarcaciones territoriales (Proyecto, Art. 30. G. I.) Después de la cantidad mínima de participación, 
el siguiente requisito de validez es el criterio de mayoría. Respecto a la revocación del mandato, el Proyecto Mancera era mejor, sus resultados serían obligatorios siempre que se manifestara a favor de esta, al menos el mismo número de votos con los que la persona titular del cargo fue electa, en el ámbito respectivo (Art. 30. G.3.) Eso es lo justo.

Sin embargo, los redactores de la Constitución querían asegurarse de que no serían defenestrados por los electores. Expresamente, sobre la revocación de mandato fija como criterios de obligatoriedad: «siempre que participe al menos el cuarenta por ciento de las personas inscritas en el listado nominal de electores del ámbito respectivo y que de estas el sesenta por ciento se manifieste a favor de la revocación». ${ }^{17}$

Se alinea con el criterio constitucional del $40 \%$ de participación, pero hace inalcanzable el 60\% de votos por la revocación, casi la misma imposibilidad que el $65 \%$ fijado por la Constitución de Sinaloa. Olvidaron que la revocación no se dirige contra el sistema electoral; se aplica a individuos. Por eso, el criterio justo de validez debiera ser mínimamente el número de votos obtenido por el destituido (Art. 25. H.3).

No es de esperar una avalancha de referendos revocatorios, los miles de cargos estarán a salvo; de cualquier modo, las experiencias singulares son aleccionadoras. El referéndum revocatorio es más que nada un instrumento disuasivo y correctivo en manos del soberano y un castigo contra quienes tergiversen los principios de representatividad e interés público.

El derecho a la consulta debe cobrar una amplitud tal que impulse la democratización de la sociedad misma, el derecho a ser consultados y a consultarse a sí misma, en cualquier segmento social, organismo y organización social. Al respecto, el Proyecto presentado por el Jefe de Gobierno expresaba

${ }^{17}$ No es tampoco una novedad. Las constituciones políticas de Jalisco y Oaxaca ya contienen este criterio de validez de la revocación: "por lo menos la misma cantidad de ciudadanos que lo hicieron en el proceso electoral donde resultó electo» (Título virI), o un número superior al que obtuvo el gobernador en esa votación (Art. 25. C. III). La Constitución de Venezuela lo estableció desde 1999 a partir de una participación de 25 por ciento. En el extremo opuesto se encuentra la Constitución de Sinaloa, que fija 65\% de los electores inscritos en el listado nominal; además, el Congreso debe aprobarla por unanimidad en el caso del gobernador, y de las dos terceras partes en el caso de los diputados (Art. 30. XLI) (Gamboa \& Ayala, 2016, pp. I5-16, 26-27, 46). 
una idea difusa que apunta a la facultad de convocar consultas por organismos sociales "por sí solos o en colaboración» con las autoridades, entre ellos alude a asambleas ciudadanas, comités ciudadanos, los consejos ciudadanos y consejos de los pueblos. Se da por supuesto que el principal mecanismo de la consulta es el voto en urnas, pero ańade foros «u otro instrumento» (Proyecto, Art. 30. E.I.).

Con este planteamiento se reconocería el derecho de los ciudadanos a autoconvocarse en demarcaciones territoriales y en la Ciudad. El derecho a la consulta debería ser extensivo a todas las organizaciones sociales, tales como sindicatos y organismos de la sociedad civil, y a sectores sociales tales como el ocupacional, género, organización social, comunidades unidades habitacionales, mujeres o jóvenes. En estos casos, se trataría de autoconvocatorias bajo reglas generales formalizadas (procedimientos, requisitos de la iniciativa, ámbito y vinculatoriedad). Esto sin afectar la facultad de las autoridades de convocar consultas.

La Constitución aprobada distingue dos tipos de consultas, la ciudadana y la popular. Respecto a la consulta ciudadana, no precisa el sujeto de la consulta, menciona a la ciudadanía en general; cabe suponer que se refiere a las demarcaciones y unidades territoriales en que se segmenta la Ciudad, ${ }^{18}$ pero se puede interpretar que se puede consultar a determinados sectores sociales; también remite al reconocimiento que hace al «derecho de los pueblos y barrios originarios y comunidades indígenas, residentes a ser consultadas» (25. A.6) La segunda forma es la consulta popular; se emplea para los electores de toda la Ciudad, lo que a su vez se vincula con los métodos de plebiscito y referéndum.

El artículo 35 de la Constitución federal fija el 2\% de los inscritos en la lista nominal de electores tan solo para la petición de «consulta ciudadana», y este criterio se ha copiado en la Constitución de la Ciudad para las consultas ciudadanas y populares. Las autoridades someterán «a consideración de las y los ciudadanos cualquier tema que tenga impacto trascendental

${ }^{\text {I8 }}$ Las antes llamadas Delegaciones son hoy nombradas Alcaldías; estas, a su vez, se subdividen en unidades territoriales, cada una de ellas tendrá una asamblea ciudadana con facultades de deliberación y decisión en asuntos de carácter social, colectivo y comunitario (Constitución de la Ciudad de México, Arts. 52 y 56). 
en los distintos ámbitos temáticos o territoriales de la Ciudad», a solicitud de al menos $2 \%$ de los inscritos en la lista nominal del ámbito territorial correspondiente (Art. 25. E).

En el caso de la consulta popular, en vez de decir «cualquier» tema dice «sobre temas de trascendencia de la Ciudad»; ¿quién valora dicha trascendencia? La solicitud la hacen autoridades, al menos $2 \%$ de los inscritos en el padrón de la Ciudad y también el Io\% de los Comités Ciudadanos, Asambleas Ciudadanas o de pueblos, barrios originarios y comunidades indígenas (Art. 25. F) Falta definir cada una de estas entidades sociales, lo cual es una dificultad práctica; por ejemplo, ¿una combinación de ellas?, ¿cuál es su representatividad?, y así en las demás figuras.

La consulta popular se celebrará el mismo día de la jornada electoral local, pero incomprensiblemente prohíbe que se lleven a cabo ese día «Ningún «instrumento de participación ciudadana», o sea, en demarcaciones submunicipales. Conforme a esta redacción, se podría consultar sobre varios temas al mismo tiempo, pero no las pequeñas consultas, probablemente influyó en la prohibición la sobrecarga que significaría para el órgano electoral la celebración de consultas ciudadanas en pequeñas zonas al mismo tiempo que las populares y las elecciones.

\section{IMPUGNACIÓN AL DERECHO A DECIDIR}

Como vemos, la aprobación de la Constitución de la Ciudad de México constituye un precedente importante en el camino de la democratización del país. Para los habitantes de la Ciudad es muy significativo que una Asamblea Constituyente haya elaborado su propia Constitución Política, misma que fue publicada por el Jefe de Gobierno de la Ciudad el 5 de febrero de 2017. Previamente, el Congreso de la Unión había reconocido a la Ciudad como «entidad federativa», un escamoteo innecesario para no llamarla estado federado. Mucho se debatió sobre si debía someterse a referéndum aprobatorio, pero el temor a la deliberación pública lo impidió.

Es un acontecimiento histórico después de una larga trayectoria de intentos para recuperar la calidad de entidad federativa que le fue arrebatada por el gobierno en I928 (Vásquez, 20I6, pp. 28-29). En la circunstancia, se 
atribuyeron el mérito de semejante logro los partidos, el Jefe de Gobierno de la Ciudad Miguel Ángel Mancera y el presidente Enrique Peña. No obstante, los capitalinos saben que fue el oficialismo el que suprimió la organización municipal de su territorio, la elección del gobernador y la asamblea de representantes; durante décadas, el PRI le negó a la Ciudad el estatus de entidad autónoma. Los capitalinos en varias generaciones lucharon por el estado 32; un lugar inolvidable en ese trayecto lo ocupa la consulta auténticamente ciudadana de 1993 con la aprobación de 320 mil convencidos, acontecimiento al que se suman tantas otras consultas y movimientos independientes que se han ido acumulando en la conciencia colectiva. Toca ahora a los habitantes de la capital ejercer a fondo sus nuevas adquisiciones.

El mismo bloque en el poder, que ignoró y combatió la persistente opinión pública, ahora concede, pero no del todo, porque varios artículos fueron impugnados ante la Suprema Corte de Justicia de la Nación por funcionarios del gobierno federal y partidos políticos, con el fin de restringir derechos ciudadanos innovadores. Finalmente, la SCJN resolvió positivamente (SCJN, Sesión Pública Núm. 86, 28 de agosto de 20I8, pp. 2I-22.)

El proceso comenzó con desconfianza, pues se diseñó una composición de la Asamblea Constituyente que frenara los impulsos democratizadores; de IOo representantes el bloque político dominante se reservó 40, además de empeñarse en ganar el mayor número posible de diputaciones por elección; maniobró para presidir las comisiones y votó contra la introducción de derechos avanzados, y los siguió impugnando con amparos. Queda por saber qué trato le dio la Asamblea Constituyente a cientos de propuestas de los ciudadanos. Pese a todo, un bloque de diputados impulsó principios y derechos muy significativos que tendrán que evolucionar. ${ }^{19}$

El referéndum revocatorio y en general el derecho a la consulta son reivindicaciones incorporadas en dicha Constitución, contra las que el conservadurismo se inconformó, en particular con el artículo 25 sobre la revocación

${ }^{19}$ Desde hace varios años, diversos grupos vienen impulsando la idea de elegir un Congreso Constituyente encargado de redactar una nueva Constitución que responda a las necesidades de nuestro tiempo. Esta inquietud se reavivó con motivo del proceso para elaborar una Constitución de la Ciudad de México (20I6-20I7), numerosos grupos ciudadanos entraron en efervescencia propositiva, cuya principal virtud ha sido generar una aspiración democrática de más largo aliento. 
de mandato impugnado por la entonces Procuraduría General de la República (PGR), interesada en proteger a la clase política de la sanción ciudadana.

Finalmente, este derecho ciudadano quedó confirmado por la SCJN no por su voluntad democratizadora, sino por no haber alcanzado la mayoría calificada de ocho votos; fueron seis magistrados quienes se pronunciaron en contra de la revocación de mandato y cinco a favor del proyecto presentado por el ministro Javier Laynez Potisk, que validaba el artículo 25 de la Constitución de la Ciudad de México (scjn, 20I8, p. 39).

Al desestimarse la impugnación iniciada por la PGR, la sCJN admitió la facultad de la Asamblea Constituyente de la Ciudad de México para legislar sobre su propio modelo ampliado de democracia, en el caso que nos ocupa, sobre el derecho ciudadano a decidir. No obstante, así como quedó el artículo en cuestión adolece todavía de restricciones que complican su práctica. Se ejercería solo una vez, a mitad de la duración del cargo. Los requisitos de validez son altos: (I) solicita la convocatoria a consulta popular al menos el IO\% de los electores (760 mil) de la lista nominal (7.6 millones en 2018); (2) el resultado será obligatorio con una participación mínima del $40 \%$ de los inscritos en el listado nominal (más de tres millones), y (3) la revocación es vinculante si el 60\% de votos son a favor de la revocación (más de I.8 millones). Los requisitos son muy altos en proporción a la necesidad de estimular el ejercicio de ese instrumento de democratización.

Del debate en la Corte destacan tres cuestionamientos antidemocráticos: las causales de la revocación, la duración del cargo y la consulta al pueblo. (I) Las causales, según la impugnación de la entonces PGR, ya están establecidas y no hay otras que justifiquen la revocación, aunque un ministro indirectamente alabó la reelección cuando los electores reconocen el buen desempeño en el cargo, pero no la destitución por mal desempeño. (2) Para los contrarios a la revocación, la duración del cargo es un periodo inamovible de tres años o de seis para los senadores y en caso de reelección de diputados y alcaldes, y no puede prolongarse ni disminuirse. El problema radica en los perjuicios que puede causar a la sociedad la prolongación en el cargo de un mal gobernante o representante; nada mejor para protegerlos que argüir que ya existe el juicio de procedencia, ya que la comisión encargada nunca dictamina. (3) El procedimiento está relacionado con otra discusión sobre el derecho ciudadano a ser consultados; la negación de este derecho pone en 
juego la democracia representativa, pues que un político sea o no representativo eso lo decide una mayoría de ciudadanos; el significado de la revocación es político, va más allá de los delitos comunes, se trata de apartar a quienes atenten contra el interés público, abusan del poder o traicionan a sus electores. La revocación es un instrumento para garantizar que el representante realmente sea representativo bajo pena de ser destituido y remplazado. Su mera existencia es disuasiva, pero sobre todo sirve para depurar a una clase política desenfrenada. Pero no es de esperar que el ejercicio de la revocación sea generalizada y desestabilizadora; la experiencia indica que es más bien casuística, previene abusos y contribuye a la participación ciudadana en los asuntos públicos.

\section{COMENTARIO FINAL}

El cambio del régimen político mexicano que desea el pueblo es claramente hacia la democracia participativa, en particular en la toma directa de decisiones y coparticipación de ellas, una dimensión de la democracia por explorar. Hemos descrito progresos significativos en la legislación de la Ciudad de México, cuyos efectos no vemos, debido a que no se han ejercido, en alguna medida porque el procedimiento es todavía restrictivo. Son progresos arrancados al régimen autoritario reacio a respetar cualquiera de las formas de la democracia, la electoral antes que ninguna.

El derecho a decidir en realidad habla de un horizonte muy amplio de formas participativas, de las que en este escrito solo se trataron tres derivadas del principio de soberanía del pueblo, definido de manera sintética de la siguiente manera: la soberanía reside en el pueblo quien la ejerce de manera directa y por medio de representantes. De su dimensión directa deriva un conjunto de modalidades participativas, entre ellas la consulta al pueblo para asuntos de interés público, incluyendo la revocación de mandato. Otras modalidades son la iniciativa legislativa popular en los diferentes niveles de gobierno: federal, estatal y municipal; el auténtico sistema de presupuesto participativo, planificación participativa; economía social y solidaria; sistema de autogestión y cogestión ciudadana de los asuntos públicos en comunidades, pueblos y ciudades; concejos ciudadanos en áreas funcionales (salud, 
educación, seguridad...), el método asambleario de deliberación, rendición de cuentas y otras.

Se habla de cambiar el régimen político, pues la consulta al pueblo exige la existencia real de libertades políticas, de reunión, asociación y manifestación, la disposición de información objetiva, suficiente y oportuna, indispensables para la formación de la opinión pública. Todas ellas condiciones para el desarrollo de la democracia participativa. Que el pueblo decida el rumbo en los municipios y comunidades, en las entidades federativas y en el país, en las organizaciones sociales y en los vecindarios. La consulta al pueblo es el vehículo para definir el proyecto alternativo de nación. Si no es ahora será mañana.

\section{REFERENCIAS}

Asamblea Constituyente de la Ciudad de México. (2016) Proyecto de Constitucion Política de la Ciudad de México. Recuperado de http://gaceta.diputados.gob.mx/ACCM/Doc/ProyectoConstI5sep.pdf.

Ballinas, V. (2I de abril de 20I4), El Senado debe entregar hoy el formato para recolectar firmas contra la reforma energética. La Jornada. Recuperado de https://www.jornada.com.mx/20I4/O4/2I/ politica/oo7n2pol

Bárcena, J. (20I4). "El derecho a decidir y sus aporías democráticas". En J. J. Solozabal, La autodeterminación a debate (pág. 224). Madrid: Editorial Pablo Iglesias.

Burdeau, G. (1985). Tratado de Ciencia Política (Vols. Tomo II, Vol. I, pp I-45I). México: UNAM.

De Carreras, F. (20I4). El derecho a no decidir pero si a salir del maldito embrollo. En J. J. Solozabal, La autodeterminación a debate (p. 224). España: Editorial Pablo Iglesias.

De la redacción (Io de noviembre de 20I6). Insta onu a México cumplir con consultar a pueblos indígenas sobre proyectos y leyes. La jornada. Recuperado de https://www.jornada.com.mx/20I6/II/Io/ politica/o22nıpol; José Antonio Román, J. A. (I3 de noviembre 
de 20I6). Exhorta la CNDH a presentar iniciativa sobre consulta a pueblos indígenas. La Jornada. Recuperado de https://www. jornada.com.mx/2016/II/I3/politica/oo3n2pol

Diario Oficial de la Federación (I9I7, 5 de febrero). Constitución Política de los Estados Unidos Mexicanos. Recuperado de http:// www.diputados.gob.mx/LeyesBiblio/ref/cpeum/CPEUM_orig_ offebigi7.pdf

Diario Oficial de la Federación (2016, I8 de julio). Ley Federal de Responsabilidades de los Servidores Públicos. Secretaria de la Función Pública. Recuperado de http://dof.gob.mx/nota_detalle.php?codigo $=5445048 \&$ fecha $=18 / 07 / 2016$

Diario Oficial de la Federación (2017, 5 de febrero). Decreto por el que se expide la Constitución Política de la Ciudad de México. Recuperado de https://dof.gob.mx/nota_detalle.php?codigo $=5470989 \&$ fecha $=05 / 02 / 2017$

Gamboa, C., y Ayala, A. (2006). Desaparición de poderes. Estudio teórico doctrinal de antecedentes constitucionales e históricos, y de iniciativas presentadas. México: Centro de Documentación y Análisis, Cámara de Diputados, Lx Legislatura.

Gamboa, C., y Ayala, A. (2016). Revocación de Mandato. Estudio Comparativo a nivel local e internacional, y de iniciativas presentadas en el tema. México: Cámara de Diputados, Lxiır Legislatura.

Garduño, R, y Méndez, E. (Io de abril de 20I4), Diputados ratifican los ajustes del Senado a la iniciativa de consulta ciudadana. La Jornada. Recuperado de https://www.jornada.com.mx/20I4/o4/Io/ politica/oI2nipol

Garduño, R. (I2 de febrero de 20I7), La revocación de mandato, congelada en el Congreso y poco clara en estados. La Jornada. Recuperado de https://www.jornada.com.mx/2017/02/I2/politica/oo9nipol

Garduño, R. (6 de marzo de 2016) Archivados en San Lázaro, 320 expedientes de juicio político La Jornada. Recuperado de https:// www.jornada.com.mx/20I6/03/o6/politica/oıınıpol

Garduño, R. y Méndez, E. (22 de abril de 2016). Solicitudes recientes de juicio político pasarán a una larga lista de espera. La Jorna- 
da. Recuperado de https://www.jornada.com.mx/2016/04/22/ politica/oo8nipol

Garduño, R. y Méndez, E. (5 de febrero de 20I4). Aprueban en San Lázaro reforma para reglamentar las iniciativas ciudadanas. La Jornada. Recuperado de https://www.jornada.com.mx/2014/02/05/ politica/or3n2pol

González, M. (1987). La intervención federal en la desaparición de poderes. México: Universidad Nacional Autónoma de México.

Hamon, F. (2007). Le réferéndum. Documents réunis et commentés, 2I(I), I-72.

Harvey, D. (2005). El “nuevo Imperialismo: acumulación por desposesión. Buenos Aires: Clacso.

Hernández, H., y Fernández, L. (2013). Democracia directa en la ciudad de México: retos y perspectivas. México: Fundacion Friedrich Ebert en México.

Jesús Aranda (3I de octubre de 20I4). Declara la Corte la improcedencia de las consultas propuestas por Morena y PRD. La Jornada. Recuperado de https://www.jornada.com.mx/20I4/ro/3I/politica/or6nipol

Méndez, E. (I5 de marzo de 2016), Instalan la sección instructora; revisará petición para desaforar a chapodiputada. La Jornada. Recuperado de https:/www.jornada.com.mx/2016/03/15/politica/or2n2pol

Méndez, E. (8 de abril de 20I4), Diputados aprobarán mañana la ley de consulta popular. La Jornada. Recuperado de https://www. jornada.com.mx/20I4/04/o8/politica/orinipol

Méndez, E. y Garduño, R. (I de marzo de 2017). Hoy desecharán en San Lázaro 90 de 36r solicitudes de juicio político. La Jornada. Recuperado de https://www.jornada.com.mx/2017/o3/or/politica/or7n2pol

Méndez, E. y Garduño, R. (30 de marzo de 20I6) Eventual juicio político contra Javier Duarte causa choque entre diputados de PAN y PRI. La Jornada. Recuperado de https:/www.jornada.com. $\mathrm{mx} / 2016 / 03 / 30 /$ politica/or2nıpol 
Méndez, E. y Garduño, R. (3I de marzo de 20I6). Ultimátum judicial a legisladores para integrar Subcomisión de Examen Previo. La Jornada. Recuperado de https://www.jornada.com.mx/2016/03/3I/ politica/oo3n2pol

Muñiz, E. (20 de abril de 20I6). Aprueban en Nu la revocación de mandato del gobernador y alcaldes. La Jornada. Recuperado de https:// www.jornada.com.mx/20I6/o4/20/politica/or7n3pol

Nuncio, A. (28 de abril de 20I6). Revocación de mandato y participación ciudadana. La jornada, pp.i9.

Parametria. (20I4). La consulta popular en México. México: Parametría sA de CV. Recuperado de http://www.parametria.com.mx/carta_parametrica.php? $\mathrm{cp}=4703$

Participando por México A. C. (20I6). Reporte de Hallazgos a partir de la integración de las bases de datos de mecanismos de participación ciudadana a nivel municipal en México 2015. Recuperado de http://mpcmx.org/content/tuning/Reporte_de_hallazgos_ MPCM.pdf

Rendón, A. (20I0). La consulta al pueblo. Formas de la democracia semidirecta. México: Itaca-UAM.

Ridao, J. (20I4). El derecho a decidir. Una salida para Cataluña y España. Barcelona: RBA Actualidad.

Suprema Corte de Justicia. (28 de agosto de 20I8). Sesión pública núm. 86. México.

Tajadura Tejada, J. (20I4). El derecho a decidir, el Estado de derecho y la democracia. En J. J. Solozabal, La autodeterminación a debate. España: Fundación Pable Igesias.

Vásquez, J. (20I6.) Distrito Federal: Historia de las Instituciones Jurídicas. México: Instituto de Investigaciones Jurídica-UnAM.

Víctor Ballinas, V. y Becerril, A. (20 de marzo de 20I4). La reforma energética, golpe de Estado constitucional, sostiene Manuel Bartlett. La Jornada. Recuperado de https://www.jornada.com. $\mathrm{mx} / 2014 / 03 / 20 /$ politica/or8nipol

Welp, Y. (2009). El referéndum contra el status quo. Análisis de Ecuador, Venezuela, Perú y Bolivia. Dialogos Latinoamericanos, (I6), I36-I55. Recuperado de https://www.academia.edu/2654966/ 
Armando Rendón Corona

El_refer\%C3\%Agndum_contra_el_status_quo._An\%C3\%Arlisis_de_Ecuador_Venezuela_Per\%C3\%BA_y_Bolivia. 